\title{
Development and characterisation of a state-of-the-art GOME-2 formaldehyde air-mass factor algorithm
}

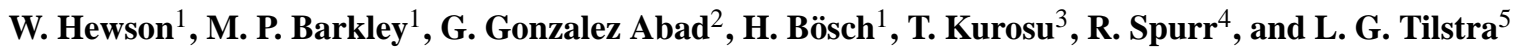 \\ ${ }^{1}$ EOS Group, Department of Physics and Astronomy, University of Leicester, Leicester, UK \\ ${ }^{2}$ Atomic and Molecular Physics Division, Harvard-Smithsonian Center for Astrophysics, Cambridge, MA, USA \\ ${ }^{3}$ NASA Jet Propulsion Laboratory, Pasadena, CA, USA \\ ${ }^{4}$ RT Solutions Inc, Cambridge, MA, USA \\ ${ }^{5}$ Royal Netherlands Meteorological Institute (KNMI), De Bilt, the Netherlands
}

Correspondence to: M. P. Barkley (mpb14@le.ac.uk)

Received: 11 August 2014 - Published in Atmos. Meas. Tech. Discuss.: 27 January 2015

Revised: 29 August 2015 - Accepted: 11 September 2015 - Published: 5 October 2015

\begin{abstract}
Space-borne observations of formaldehyde (HCHO) are frequently used to derive surface emissions of isoprene, an important biogenic volatile organic compound. The conversion of retrieved HCHO slant column concentrations from satellite line-of-sight measurements to vertical columns is determined through application of an air mass factor (AMF), accounting for instrument viewing geometry, radiative transfer, and vertical profile of the absorber in the atmosphere. This step in the trace gas retrieval is subject to large errors. This work presents the AMF algorithm in use at the University of Leicester (UoL), which introduces scenespecific variables into a per-observation full radiative transfer AMF calculation, including increasing spatial resolution of key environmental parameter databases, input variable area weighting, instrument-specific scattering weight calculation, and inclusion of an ozone vertical profile climatology. Application of these updates to $\mathrm{HCHO}$ slant columns from the GOME-2 instrument is shown to typically adjust the AMF by $\pm 20 \%$, compared to a reference algorithm without these advanced parameterisations. On average the GOME-2 AMFs increase by $4 \%$, with over $70 \%$ of locations having an AMF of 0-20\% larger than originally, largely resulting from the use of the latest GOME-2 reflectance product. Furthermore, the new UoL algorithm also incorporates a full radiative transfer error calculation for each scene to help characterise AMF uncertainties. Global median AMF errors are typically $50-60 \%$, and are driven by uncertainties in the $\mathrm{HCHO}$ profile shape and its vertical distribution relative to
\end{abstract}

clouds and aerosols. If uncertainty on the a priori $\mathrm{HCHO}$ profile is relatively small $(<10 \%)$ then the median AMF total error decreases to about $30-40 \%$.

\section{Introduction}

Formaldehyde (HCHO) is produced in the atmosphere from the oxidation of a wide range of volatile organic compounds (VOCs), emitted from human activities, vegetation and biomass burning (Stavrakou et al., 2009a). Direct HCHO emissions from vegetation and industry are additional minor sources. The main sinks of HCHO are photolysis and reaction with the hydroxyl radical $(\mathrm{OH})$, which give it a short atmospheric lifetime of only a few hours, thus making it an important tracer of localised active photochemistry and a useful proxy for determining underlying surface VOC emissions. In particular, there has been widespread use of satellite measurements of $\mathrm{HCHO}$ integrated columns to constrain the emissions of isoprene, the dominant biogenic VOC (BVOC) emitted from terrestrial vegetation and a high $\mathrm{HCHO}$ yield precursor, at both regional and global scales (e.g. Palmer et al., 2003, 2006; Fu et al., 2007; Millet et al., 2006, 2008; Curci et al., 2010; Marais et al., 2012; Barkley et al., 2008, 2013; Stavrakou et al., 2009b, 2014). However, reducing uncertainties associated with inferred (or top-down) emission estimates depends critically on the accuracy of the retrieved HCHO column observations (Barkley et al., 2013). 
Tropospheric vertical HCHO columns have been retrieved by a number of groups from solar backscatter instruments such as GOME (Chance et al., 2000; Wittrock et al., 2000, 2006; De Smedt et al., 2008), SCIAMACHY (De Smedt et al., 2008), OMI (Kurosu et al., 2004; González Abad et al., 2015) and GOME-2 (De Smedt et al., 2008; Hewson et al., 2013). This process typically involves three stages. First, HCHO slant columns along the instrument line of sight are obtained via the spectral fitting of trace gas absorption cross sections to observed UV radiance measurements (typically in the wavelength range $\sim 325-360 \mathrm{~nm})$. Second, observed $\mathrm{HCHO}$ column residual biases (e.g. due to ozone interference) over the remote Pacific Ocean are then removed using a standard reference sector correction (e.g. De Smedt et al., 2008, 2012). Lastly, the slant columns are divided by an air mass factor (AMF) to produce geophysical $\mathrm{HCHO}$ vertical columns (independent of the satellite viewing geometry), which are then re-normalised using the HCHO background field from a chemical transport model. Reported final errors on gridded monthly mean vertical columns are approximately 20-60\% (De Smedt et al., 2008, 2012; Barkley et al., 2013), depending on the instrument and averaging method.

Over the oceans and regions with low HCHO, the vertical column error is mainly influenced by the slant column fitting error, whereas over continental enhancements, the errors associated with the AMF become more relevant. Given the primary use of $\mathrm{HCHO}$ columns is to constrain surface VOC emissions, it is therefore important to fully characterise the AMF and its error for each individual instrument and retrieval (Barkley et al., 2012). The AMF represents observational sensitivity along the light path, relative to the vertical, accounting for the atmospheric and measurement state (Palmer et al., 2001). It is generally computed by a multiplescattering radiative transfer model, using a priori information on aerosols, clouds, the HCHO vertical profile and surface reflectance, with the uncertainty of each influencing the final AMF error. Past studies, which have examined the HCHO AMF sensitivity to these parameters, show the approximate errors associated with aerosols are $20-50 \%$, clouds $20-30 \%$, and surface reflectance $20 \%$ (see e.g. Palmer et al., 2006; Fu et al., 2007; De Smedt et al., 2008; Barkley et al., 2012). AMF errors arising from the $\mathrm{HCHO}$ profile vary depending on its relative vertical distribution to aerosols and clouds, but are of the order of 20-40\% (De Smedt et al., 2008; Barkley et al., 2012). The HCHO profile is also subject to chemistry transport model (CTM) errors, such as choice of BVOC emission inventory or chemical reaction scheme, which affect its accuracy (Barkley et al., 2012).

There is, therefore, a pressing need to improve AMF calculations and reduce uncertainties wherever possible. Accordingly, this paper details a new algorithm, which attempts to improve the accuracy of HCHO AMFs by performing scenespecific full-radiative transfer calculations and through more advanced treatment of the input a priori information. Furthermore, the algorithm includes a full radiative transfer er- ror calculation for each observation, to help quantify AMF uncertainties and their corresponding spatial and temporal variation. The new AMF algorithm is applied to retrieved GOME-2 HCHO slant columns, to determine its subsequent impact on the tropospheric $\mathrm{HCHO}$ vertical columns.

The paper is structured as follows. Sections 2 and 3 provide an overview and a brief review of contemporary UV-Vis AMF calculations, respectively. Section 4 describes the default University of Leicester (UoL) GOME-2 AMF scheme, which establishes a reference to assess subsequent AMF updates. Section 5 outlines the major updates to the UoL AMF algorithm and assesses their subsequent impact. An assessment of AMF errors is presented in Sect. 6. The paper concludes with a short summary.

\section{Calculation of UV-Vis AMFs}

The air mass factor for a given observation is defined as the ratio of the trace gas slant column density to its vertical column density. In a non-scattering atmosphere, the satellite viewing geometry dictates the light path and hence a geometrical air mass factor $\left(\mathrm{AMF}_{\mathrm{G}}\right)$ can be calculated by

$\mathrm{AMF}_{\mathrm{G}}=\frac{1}{\cos \theta_{\mathrm{SZA}}}+\frac{1}{\cos \theta_{\mathrm{VZA}}}$,

where $\theta_{\mathrm{SZA}}$ and $\theta_{\mathrm{VZA}}$ are the solar-zenith and viewing-zenith angles, respectively. In the real atmosphere, Rayleigh scattering and scattering from aerosols and clouds strongly influence the photon path length. To account for these effects, current UV-Vis trace gas retrievals typically calculate AMFs using the approach of Palmer et al. (2001), which decouples atmospheric scattering from the trace gas vertical profile, via

$\mathrm{AMF}=\mathrm{AMF}_{\mathrm{G}} \int_{0}^{\infty} w(z) S(z) \mathrm{d} z$,

where $w(z)$ are scattering weights that represent the sensitivity of the backscattered radiance to the absorber abundance at each altitude, and $S(z)$ is a normalised shape factor that describes the trace gas vertical distribution. The scattering weights are defined as

$w(z)=-\frac{1}{\mathrm{AMF}_{\mathrm{G}}} \frac{\alpha(z)}{\alpha_{\mathrm{e}}} \frac{\partial(\ln I)}{\partial \tau}$,

where $\alpha(z)$ is the absorption cross section, $\alpha_{\mathrm{e}}$ is the effective absorption cross section, (a weighted average over the tropospheric column), and $\partial \tau$ is the incremental optical depth. The scattering weights are computed in a similar approach for clear and cloudy conditions using a radiative transfer model (RTM), and are a function of wavelength $(\lambda)$, surface pressure $\left(P_{\mathrm{S}}\right)$, surface albedo $(A)$ and the solar/viewing geometry; the shape factor is usually provided by an offline CTM. For cloudy conditions, cloud fraction 
Table 1. Comparison of three different contemporary HCHO AMF calculations. Readers are referred to cited references for full details.

\begin{tabular}{|c|c|c|c|}
\hline & Barkley et al. (2013) & De Smedt et al. (2012) & González Abad et al. (2015) \\
\hline Instrument(s) & $\begin{array}{l}\text { SCIAMACHY } \\
\quad \& \text { OMI }\end{array}$ & $\begin{array}{l}\text { GOME, SCIAMACHY } \\
\text { \& GOME-2 }\end{array}$ & OMI \\
\hline RTM & LIDORT v2.3 & LIDORT v3.0 & VLIDORT v2.4 \\
\hline CTM & $\begin{array}{c}\text { GEOS-Chem } \\
\text { Nested } 0.67^{\circ} \times 0.5^{\circ} \text { grid }\end{array}$ & $\begin{array}{c}\text { IMAGES v2 } \\
\text { Global } 2^{\circ} \times 2.5^{\circ} \text { grid }\end{array}$ & $\begin{array}{c}\text { GEOS-Chem } \\
\text { Global } 2^{\circ} \times 2.5^{\circ} \text { grid }\end{array}$ \\
\hline A priori profile & $\begin{array}{l}\text { GEOS-Chem } \\
\text { monthly mean profiles }\end{array}$ & $\begin{array}{l}\text { IMAGESv2 } \\
\text { daily profiles }\end{array}$ & $\begin{array}{l}\text { GEOS-Chem } \\
\text { monthly mean profiles }\end{array}$ \\
\hline Surface pressure & GEOS-Chem $\left(0.67^{\circ} \times 0.5^{\circ}\right)$ & $\begin{array}{c}\text { IMAGESv2 }\left(2^{\circ} \times 2.5^{\circ}\right) \\
\text { adjusted by mean elevation }\end{array}$ & GEOS-Chem $\left(2^{\circ} \times 2.5^{\circ}\right)$ \\
\hline Surface elevation & - & not specified & - \\
\hline Surface albedo & $\begin{array}{l}\text { Herman and Celarier }(1997) \\
\text { monthly climatology } \\
\text { regridded to } 0.67^{\circ} \times 0.5^{\circ} \\
\quad(\lambda \sim 360 \mathrm{~nm})\end{array}$ & $\begin{array}{l}\text { Kleipool et al. }(2008) \\
\text { monthly climatology } \\
\text { at } 0.5^{\circ} \times 0.5^{\circ} \\
(\lambda=342 \mathrm{~nm})\end{array}$ & $\begin{array}{c}\text { Kleipool et al. (2008) } \\
\text { monthly climatology } \\
\text { at } 0.5^{\circ} \times 0.5^{\circ} \\
\text { (interpolated to } \lambda \sim 340 \mathrm{~nm} \text { ) }\end{array}$ \\
\hline Aerosol correction & $\begin{array}{l}\text { GEOS-Chem monthly } \\
\text { mean AOD profiles }\end{array}$ & $\begin{array}{l}\text { Implicit treatment } \\
\text { using cloud algorithm }\end{array}$ & $\begin{array}{l}\text { Implicit treatment } \\
\text { using cloud algorithm }\end{array}$ \\
\hline Pixel calculation & $\begin{array}{l}\text { Interpolated from } \\
\text { look-up table }\end{array}$ & $\begin{array}{l}\text { Interpolated from } \\
\text { look-up table }\end{array}$ & $\begin{array}{l}\text { Interpolated from } \\
\text { look-up table }\end{array}$ \\
\hline
\end{tabular}

and cloud-top pressure are also inputs, usually taken from the appropriate satellite cloud algorithm. To account for partially cloudy scenes the approach of Martin et al. (2002) is commonly adopted, which assumes the total AMF is the reflectivity-weighted average of the air mass factors for the clear $\left(\mathrm{AMF}_{\mathrm{clr}}\right)$ and cloudy $\left(\mathrm{AMF}_{\mathrm{cld}}\right)$ pixel sub-scenes.

Calculation of accurate AMFs therefore requires each retrieval to select the best available a priori information, and the most suitable RTM and CTM. In the next section different approaches for calculating the AMFs are discussed.

\section{Current AMF algorithms}

While the basic method of calculation mostly remains the same for all AMFs (i.e. that of Palmer et al., 2001), AMF algorithms differ widely in the temporal and spatial resolution of a priori databases, choice of RTM, and their treatment of aerosols. Brief summaries of state-of-the-art HCHO and analogous tropospheric nitrogen dioxide $\left(\mathrm{NO}_{2}\right) \mathrm{AMF}$ algorithms are presented in Tables 1 and 2, respectively.

The importance of using an accurate and spatially resolved surface reflectance product in AMF calculations has been cited as one of the most significant factors in reducing AMF error (Boersma et al., 2004; Zhou et al., 2010). Highly reflecting surfaces increase measurement sensitivity to boundary layer trace gases, whereas the converse is true for dull surfaces. Thus, an ideal albedo data set must resolve finescale features, otherwise calculated AMFs will be erroneous. For example, a MODIS $0.05^{\circ} \times 0.05^{\circ} 16$-day mean albedo product is utilised in the $\mathrm{OMI} \mathrm{NO}_{2}$ retrieval by Russell et al. (2011), since it removes artificial $\mathrm{NO}_{2}$ features evident when a coarser GOME $1^{\circ} \times 1^{\circ}$ albedo climatology is used. Albedo data sets currently available include: Herman and Celarier (1997), Koelemeijer et al. (2003), or a combination of the two, e.g. Boersma et al. (2004), and the Kleipool et al. (2008) monthly climatology derived from OMI. Until recently, a GOME-2 albedo data set was not available; surface reflectances applied for its $\mathrm{HCHO}$ AMF calculations were derived from satellite instruments with different observation times and viewing geometries (e.g. De Smedt et al., 2012; Hewson et al., 2013). However, there now exists an opportunity to use scene-specific albedos consistent with GOME-2, using the new GOME-2 surface Lambertian-equivalent reflectance (LER) product developed by Tilstra et al. (2014a).

Trace gas a priori profiles are usually taken from a CTM, or alternatively a climatology. Retrieval groups differ in their CTM choice, whose complexity often varies, using spatial resolutions ranging from a few $\mathrm{km}^{2}$ (Heckel et al., 2011; Russell et al., 2011) in regional studies to $4 \times 5^{\circ}$ for global use (De Smedt et al., 2008; Hewson et al., 2013). Monthly mean or daily profiles can be used, although the latter are expected to provide a more detailed evolution of tropospheric chemistry. For example, Valks et al. (2011) found $\mathrm{NO}_{2} \mathrm{AMF}$ uncertainties of about $10 \%$ due to monthly CTM fields by comparing against daily values calculated over the same time period. Most advanced AMF schemes also adjust the trace gas profile according to the mean elevation over the satel- 
Table 2. Comparison of four different contemporary $\mathrm{NO}_{2} \mathrm{AMF}$ calculations. Readers are referred to cited references for full details.

\begin{tabular}{|c|c|c|c|c|}
\hline & Boersma et al. (2011a) & Lin et al. (2014) & Russell et al. (2011) & Valks et al. (2011) \\
\hline Instrument(s) & OMI & OMI & OMI & GOME-2 \\
\hline Application & Global & Regional & Regional & Global \\
\hline RTM & KNMI DAK & LIDORT v3.6 & TOMRAD & LIDORT v3.3 \\
\hline CTM & $\begin{array}{c}\text { TM4 } \\
\text { Global } 2^{\circ} \times 3^{\circ} \text { grid }\end{array}$ & $\begin{array}{c}\text { GEOS-Chem } \\
\text { Nested } 0.5^{\circ} \times 0.67^{\circ} \text { grid }\end{array}$ & $\begin{array}{c}\text { WRF-Chem } \\
\text { Regional } 4 \mathrm{~km} \times 4 \mathrm{~km} \text { grid }\end{array}$ & $\begin{array}{c}\text { MOZART v2 } \\
\text { Global } 1.85^{\circ} \times 1.85^{\circ} \text { grid }\end{array}$ \\
\hline A priori profile & $\begin{array}{c}\text { TM4 } \\
\text { daily profiles }\end{array}$ & $\begin{array}{l}\text { GEOS-CHEM } \\
\text { daily profiles }\end{array}$ & $\begin{array}{l}\text { WRF-Chem } \\
\text { monthly mean profiles }\end{array}$ & $\begin{array}{c}\text { MOZART } \\
\text { monthly mean profiles }\end{array}$ \\
\hline Surface pressure & $\begin{array}{c}\text { TM4 }\left(2^{\circ} \times 3^{\circ}\right) \\
\text { adjusted by mean elevation }\end{array}$ & $\begin{array}{l}\text { GEOS-Chem }\left(0.67^{\circ} \times 0.5^{\circ}\right) \\
\text { adjusted by mean elevation }\end{array}$ & $\begin{array}{l}\text { WRF-Chem }(4 \mathrm{~km} \times 4 \mathrm{~km} \text { grid }) \\
\text { adjusted by mean elevation }\end{array}$ & $\begin{array}{l}\text { MOZART }\left(1.85^{\circ} \times 1.85^{\circ}\right) \\
\text { adjusted by mean elevation }\end{array}$ \\
\hline Surface elevation & DEM-3km & GMTED2010 & GLOBE $1 \mathrm{~km} \times 1 \mathrm{~km}$ & GOTOPO30 $1 \mathrm{~km} \times 1 \mathrm{~km}$ \\
\hline Surface albedo & $\begin{array}{l}\text { Kleipool et al. }(2008) \\
\text { monthly climatology } \\
\text { at } 0.5^{\circ} \times 0.5^{\circ} \\
(\lambda=440 \mathrm{~nm}) \\
\text { Temporal interpolation only }\end{array}$ & $\begin{array}{l}\text { MODIS MCD43C2 BDRF } \\
\text { 16-day average } \\
\text { at } 0.05^{\circ} \times 0.05^{\circ} \\
(\lambda=440 \mathrm{~nm}) \\
\text { Temporal interpolation only }\end{array}$ & $\begin{array}{c}\text { MODIS MCD43C2 BDRF } \\
\text { 16-day average } \\
\text { at } 0.05^{\circ} \times 0.05^{\circ} \\
(\lambda=342 \mathrm{~nm}) \\
\text { Area-weighted }\end{array}$ & $\begin{array}{l}\text { Boersma et al. (2004) } \\
\text { monthly climatology } \\
\text { at } 1^{\circ} \times 1.25^{\circ} \\
(\lambda=380 \text { and } 440 \mathrm{~nm}) \\
\text { Area-weighted and } \\
\text { temporal interpolation }\end{array}$ \\
\hline Aerosol correction & $\begin{array}{l}\text { Implicit treatment } \\
\text { using cloud algorithm }\end{array}$ & $\begin{array}{c}\text { GEOS-Chem daily } \\
\text { AOD profiles } \\
\left(\mathrm{AOD}_{\lambda}=438 \mathrm{~nm}\right) \\
\text { Adjusted by AERONET, } \\
\text { MAX-DOAS and MODIS }\end{array}$ & $\begin{array}{l}\text { Implicit treatment } \\
\text { using cloud algorithm }\end{array}$ & $\begin{array}{l}\text { Implicit treatment } \\
\text { using cloud algorithm }\end{array}$ \\
\hline Pixel calculation & $\begin{array}{l}\text { Interpolated from } \\
\text { look-up table }\end{array}$ & $\begin{array}{l}\text { RTM calculation } \\
\text { for each scene }\end{array}$ & $\begin{array}{l}\text { Interpolated from } \\
\text { look-up table }\end{array}$ & $\begin{array}{l}\text { Interpolated from } \\
\text { look-up table }\end{array}$ \\
\hline
\end{tabular}

lite footprint to remove biases arising from inaccurate terrain pressure, using the surface pressure correction devised by Zhou et al. (2009). Studies have shown that for $\mathrm{NO}_{2}$ this correction can cause differences of about $\pm 20 \%$ in the tropospheric column (Schaub et al., 2007; Zhou et al., 2009; Boersma et al., 2011a; Russell et al., 2011).

Aerosol scattering and absorption can have significant impacts on HCHO observations (Fu et al., 2007; Gonzi et al., 2011; Barkley et al., 2012). In particular, biomass burning aerosols distributed high above the boundary layer can artificially enhance retrieved tropospheric vertical columns by up to $50 \%$ (Barkley et al., 2012). Current algorithms either explicitly correct for aerosol effects using modelled aerosol optical depth (AOD) profiles and properties (e.g. Barkley et al., 2012, 2013) or, alternatively, implicitly rely on corresponding cloud algorithms to correct for their presence (e.g. De Smedt et al., 2008, 2012; Boersma et al., 2011a). The presence of aerosols also affects the retrieval of cloud parameters. For example, low non-absorbing aerosol layers tend to result in an overestimation of cloud fraction and underestimate of cloud height (Boersma et al., 2004), whereas for strongly absorbing aerosols located above clouds, the retrieved cloud pressure may represent the height of the aerosol layer rather than the height of the clouds (Wang et al., 2012).

Uncertainties in cloud fraction and height also affect AMF accuracy. For a cloud fraction of 0.5 , estimates of $\mathrm{HCHO}$
AMF uncertainty can range from $30 \%$ in the presence of high cloud $(8 \mathrm{~km})$ to $50 \%$ in low cloud conditions $(<2 \mathrm{~km})$ (De Smedt et al., 2008). Analysis of measured and modelled HCHO AMFs by Millet et al. (2006) determined slightly lower biases of 10-21\% for cloud fractions 30-60\%. For $\mathrm{NO}_{2}$, Boersma et al. (2004) estimated AMF uncertainties of $0-30 \%$ arising from errors in cloud fraction and $<10 \%$ from cloud height. Hence cloud-induced AMF errors are expected to be in the range $20-30 \%$ for cloud fractions typically less than $40 \%$, depending on the observation conditions and cloud product accuracy.

AMFs for UV-Vis trace gas retrievals must also account for the absorption of UV radiation by ozone (Palmer et al., 2001). Typically a single ozone profile (e.g. US standard atmosphere) is used in the calculation of the scattering weights, with the effects of natural ozone variability not considered. However, in their calculation of SCIAMACHY and OMI $\mathrm{SO}_{2}$ AMFs, Lee et al. (2009) scaled the US total column using coincident measurements of retrieved ozone column. They found that the magnitude of the ozone correction on $\mathrm{SO}_{2}$ AMFs can be large $(>30 \%)$ under certain conditions, indicating that groups should evaluate this effect in their AMF algorithms.

Finally, retrievals either derive AMFs from pre-calculated look-up tables (LUTs), or calculate an individual AMF for each observation. AMFs derived from full RTM calcula- 
tions are expected to be more accurate since they tend to incorporate more representative a priori information and do not suffer from potential LUT interpolation errors; however, their calculation often requires considerable computational expense. Additionally, AMF errors are either estimated from error LUTs (e.g. De Smedt et al., 2008), sensitivity studies (e.g. Valks et al., 2011), or in the worst case simply quoted from relevant past studies, rather than being explicitly calculated by the RTM for each observation over the region of interest.

\section{The UoL GOME-2 HCHO retrieval}

\subsection{Slant column retrieval}

GOME-2 HCHO slant columns used in this work come from Hewson et al. (2013). In brief, slant columns are calculated with the DOAS method (Platt and Stutz, 2008), using the QDOAS analysis package (Fayt et al., 2011). The cross sections of $\mathrm{HCHO}$ and interfering absorbers $\left(\mathrm{BrO}, \mathrm{O}_{3}\right.$ and $\left.\mathrm{NO}_{2}\right)$, as well as Ring and undersampling contributions, are fitted to GOME-2 measured line-of-sight radiances after removal of broadband absorption terms with a fifth-order polynomial. Biases in the slant columns are removed using a reference sector method, by fitting a daily latitudinal polynomial to measured HCHO columns over the Pacific Ocean, between 170 and $140^{\circ} \mathrm{W}$. This latitudinal area corresponds to a region where the only background levels of $\mathrm{HCHO}$ occur due to methane oxidation. The polynomial is subtracted from all global measurements, and then AMFs are calculated and applied to obtain vertical columns, which are then renormalised to expected background concentrations through the addition of corresponding model $\mathrm{HCHO}$ columns from the same Pacific region. In the UoL retrieval, the model fields are provided by the GEOS-Chem CTM, as described in Hewson et al. (2013). Details of the GEOS-Chem simulation and the baseline University of Leicester (UoL) AMF algorithm, which explicitly calculates an AMF for each observation, are discussed in the next sections.

\subsection{GEOS-Chem chemical transport model}

The GEOS-Chem chemical transport model (version 08-0301 ) is used to simulate tropospheric chemistry at global and regional scales, and to provide daily a priori tropospheric HCHO and AOD profiles, appropriate to GOME-2's local overpass time (09:00-10:00). The model is driven by meteorological fields provided by NASA's Goddard Earth Observing System version 5 (GEOS-5) assimilation system (Rienecker et al., 2008), which are available at a native spatial resolution of $0.5^{\circ}$ latitude $\times 0.67^{\circ}$ longitude, and with 72 vertical pressure levels from the surface to $0.01 \mathrm{hPa}$. However, the resolution of the GEOS- 5 data is degraded accordingly to $2^{\circ} \times 2.5^{\circ}$ and $4^{\circ} \times 5^{\circ}$, to run GEOS-Chem globally at medium and coarse spatial scales. Additionally, over trop- ical South America where isoprene emissions are large and HCHO columns high, GEOS-Chem is employed in a oneway nested grid mode, utilising GEOS-5 default resolution to better resolve features in this key region (see Barkley et al., 2011). To ensure consistency, boundary conditions for nested South America simulation are provided by the $4^{\circ} \times 5^{\circ}$ model run. In each model configuration the vertical dimensions are also degraded to 47 pressure levels, with the lowermost layers of the model (surface $\leq 2 \mathrm{~km}$ ) approximated by 14 layers.

GEOS-Chem simulates tropospheric photochemistry taking into account major chemical species $\left(\mathrm{O}_{3}, \mathrm{NO}_{x}\right.$ and VOCs) and aerosol interactions, with a reaction scheme which consists of about 400 reactions and 80 species based on the work of Paulot et al. (2009a, b) and Mao et al. (2013). Relevant input emission inventories include the MEGAN biogenic VOC database (Guenther et al., 2006), EDGAR anthropogenic emissions (Olivier et al., 2001), and the Global Fire Emissions Database v2 (van der Werf et al., 2006). Anthropogenic emissions are overwritten with more detailed regional inventories where possible, as described in van Donkelaar et al. (2008). A detailed account of the tropical South America simulation, including updates to the chemical and dry deposition schemes which are applied in all simulations, can be found in Barkley et al. (2011).

\subsection{Baseline AMF calculation}

The baseline UoL AMF calculation uses daily data from the global GEOS-Chem $4^{\circ} \times 5^{\circ}$ simulation, with model quantities sampled at the same time and location of each observation. In this study the scattering weights and sub-scene reflectivities are generated for each observation with the LIDORT v2.3 radiative transfer model (Spurr, 2002), following Palmer et al. (2001) and Martin et al. (2002). In addition to HCHO, other atmospheric profiles used within LIDORT include GEOS-Chem AOD profiles (for mineral dust, tropospheric sulfate, black carbon, organic carbon and sea salt), and also US standard atmosphere $\mathrm{O}_{3}$ and $\mathrm{NO}_{2}$ profiles. AMFs are computed at a wavelength of $340 \mathrm{~nm}$, representative of the DOAS HCHO slant column fitting region (328.5$346 \mathrm{~nm}$ ) (Barkley et al., 2012; Hewson et al., 2013), and consistent with the Herman and Celarier (1997) Lambert equivalent reflectivity database used at $340 \mathrm{~nm}$, and CTM AODs at $340 \mathrm{~nm}$ calculated with physical aerosol optical properties based on the study of Martin et al. (2003). Cloud fraction and cloud-top pressure are taken from the most recent version of the GOME-2 FRESCO+ cloud product (Wang et al., 2008), using the Popp et al. (2011) MERIS albedo climatology for surface reflectivity values in the $\mathrm{O}_{2}$ A-band retrieval. FRESCO+ does not calculate cloud optical thickness (COT) values, thus clouds are treated as Lambertian reflectors with an albedo of 0.8, a method consistent with other studies (e.g. De Smedt et al., 2012; Barkley et al., 2013; González Abad et al., 2015). Monthly climatological maps of the $\sim 360 \mathrm{~nm}$ surface albedo, taken from the TOMS LER 


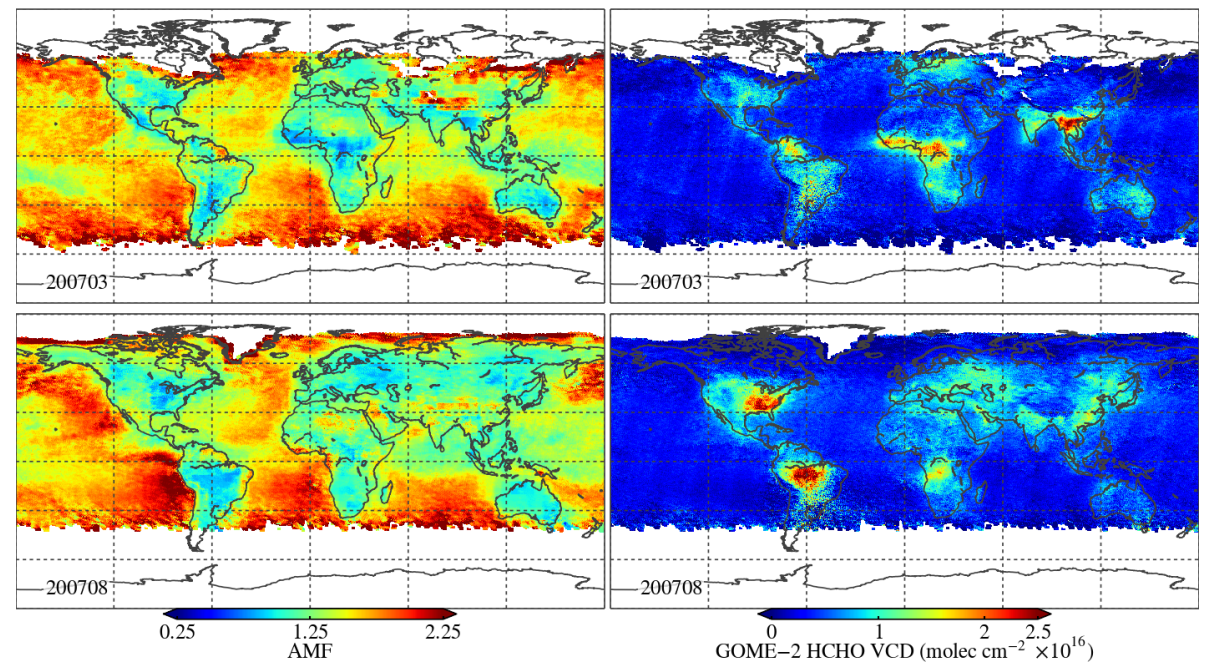

Figure 1. Monthly mean GOME-2 HCHO air mass factors (AMFs) and corresponding vertical columns (VCDs) for March and August 2007, calculated using the UoL baseline AMF algorithm (see Sect. 4.3) and gridded to $0.25^{\circ} \times 0.25^{\circ}$ using observations with cloud fractions $<40 \%$.

database (November 1978-May 1993) generated by Herman and Celarier (1997), are re-gridded to match the GEOSChem grid and used in clear-sky conditions.

Following Martin et al. (2003), we account for aerosols in the AMF calculation by representing within the LIDORT model their vertically resolved optical properties from the GEOS-Chem simulation described in Sect. 4.2. In practice, height-resolved AODs are used for the aerosol extinction (i.e. per $\mathrm{km}$ ); for aerosol scattering the AODs are weighted by the appropriate single-scattering albedo (SSA) of that aerosol type. Aerosol optical properties (black and organic carbon aerosols, mineral dust, sulfate, sea salt and water vapour) are based on the GADS (Global Aerosol Data Set) data (Köpke et al., 1997). Tabulated values are calculated offline and implemented into GEOS-Chem, as described in Martin et al. (2003), with the same values used directly in the AMF computation. In the AMF calculation itself, a humidity of $70 \%$ is assumed and we use values specific to $340 \mathrm{~nm}$, of the extinction efficiency, effective radius, SSA and the first eight terms in the Legendre expansion of the phase function $(\pi)$. At $340 \mathrm{~nm}$, the SSAs of the aerosols types are 0.2342 (black carbon), 0.9861 (organic carbon), 0.8394 (dust), 1.0 (sulfate), 1.0 (sea salt) and 1.0 (water cloud), respectively.

Using these default settings, scene-specific GOME-2 AMFs are calculated for March and August 2007, months chosen to both reflect the range of expected tropospheric $\mathrm{HCHO}$ concentrations, and provide a reference for subsequent comparisons. Figure 1 shows gridded monthly mean AMFs and HCHO vertical columns calculated from the reference sector corrected slant columns derived for the two selected months. Calculated AMFs are $0.55-3.68$ over the ocean, and 0.61-3.68 over land. Observed HCHO columns in March are generally low, whilst in August seasonal en- hancements are evident over southeast USA and the Amazon rainforest, features consistent with other GOME-2 retrievals (De Smedt et al., 2012).

\subsection{Comparison of baseline AMF versus LUT AMFs}

Previously, monthly averaged GEOS-Chem profiles have been used to compute AMF LUTs for SCIAMACHY, OMI and GOME-2, as a function of location and viewing geometry, and also surface reflectance; see e.g. Barkley et al. (2012, 2013) and Hewson et al. (2013). Whilst AMF LUTs can be calculated and applied reasonably fast, they suffer from unavoidable interpolation errors. To quantify this error source, AMF LUT tables were computed using the same GEOSChem $4^{\circ} \times 5^{\circ}$ model output, applied to the GOME-2 data, and then compared to the baseline AMF algorithm detailed in Sect. 4.3. Figure S1 in the Supplement shows the spatial maps and histogram of the AMF differences. For both March and August of 2007, nearly $90 \%$ of locations have AMF differences of up to $\pm 10 \%$, hence advocating the use of daily model profiles and full RTM calculations. The $1 \sigma$ width of fitted exponential functions to the histograms are 4 and $5 \%$ for March and August, respectively. The AMF differences are attributed to difference in $\mathrm{HCHO}$ and AOD vertical profiles, as discussed further in Sect. 5.2. Similar AMF differences, due to the use of monthly versus daily profiles, were also found for $\mathrm{NO}_{2}$ by Valks et al. (2011). 

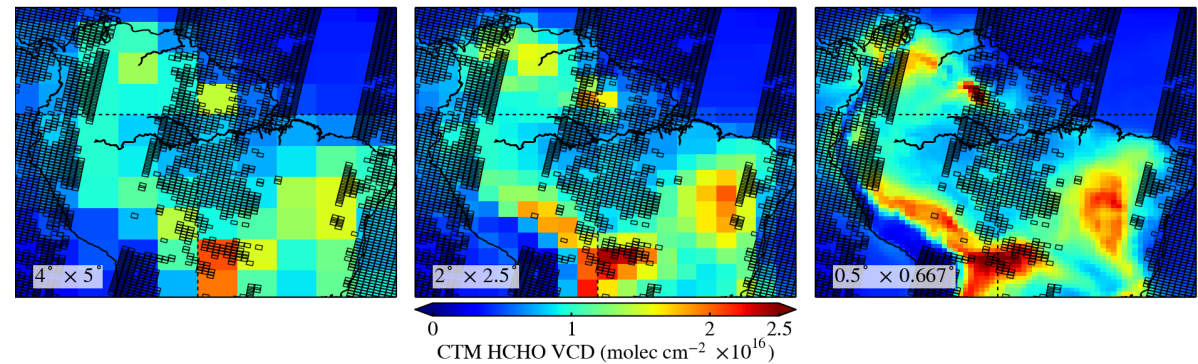

Figure 2. Model HCHO vertical columns over the Amazon simulated by GEOS-Chem at three different spatial resolutions (left to right: $4^{\circ} \times 5^{\circ}, 2^{\circ} \times 2.5^{\circ}, 0.5^{\circ} \times 0.667^{\circ}$ ). Overlain in black are three typical orbital tracks showing the footprint of each GOME-2 observation with cloud fraction $<40 \%$.
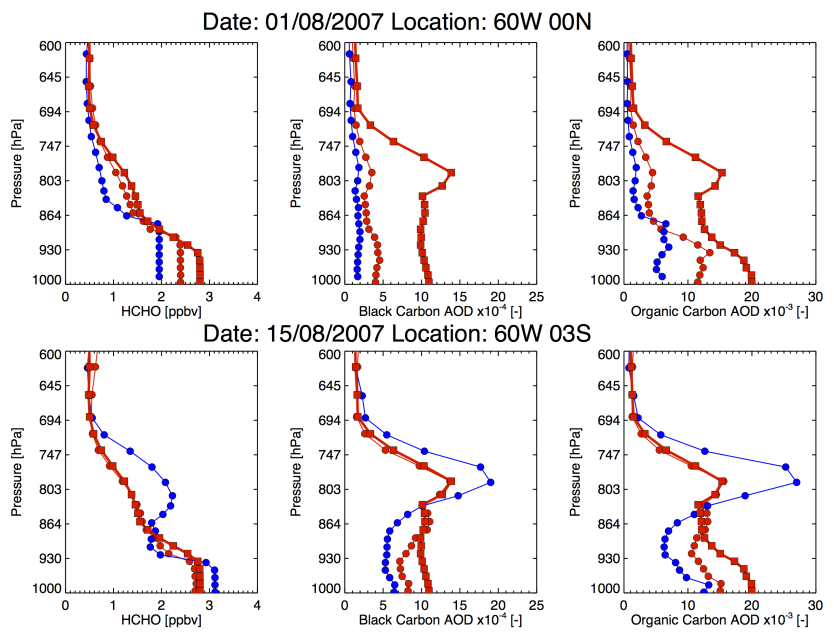

Figure 3. Vertical profiles of $\mathrm{HCHO}$, black carbon and organic carbon (AOD) simulated by GEOS-Chem at $4^{\circ} \times 5^{\circ}$ (red solid circles), and $0.5^{\circ} \times 0.667^{\circ}$ (blue solid circles) for two different locations and times. The red solid squares show the monthly mean $4^{\circ} \times 5^{\circ}$ profile used in the AMF LUT approach discussed in Sect. 4.4.

\section{UoL AMF algorithm updates}

\subsection{Overview}

To improve the UoL AMF algorithm six main updates have been applied and evaluated. These are: (1) assessment of different GEOS-Chem grid resolutions; (2) area weighting of a priori inputs to match the satellite footprint; (3) application of the Zhou et al. (2009) terrain correction; (4) an upgrade of the surface albedo database; (5) the HCHO and ozone absorption cross sections within LIDORT have been changed to match those used in the slant column retrieval, and are adjusted to account for change of GOME-2's slit function over time and also for temperature effects, and finally (6) the US Standard $\mathrm{O}_{3}$ vertical mixing ratios are replaced with climatologybased values and scaled with coincident GOME-2 total column $\mathrm{O}_{3}$ observations. The results of these improvements are as follows.

\subsection{Impact of GEOS-Chem grid resolution}

Low-resolution input databases can lead to inaccurate AMF calculations due to misrepresentation of small-scale surface features, especially over rapidly changing terrain such as land-sea boundaries and mountainous regions (Boersma et al., 2007, 2011a; Heckel et al., 2011; Russell et al., 2011; Lin et al., 2014). A nominal GOME-2 pixel covers a $80 \times 40 \mathrm{~km}^{2}$ footprint on the Earth's surface, considerably smaller than the default GEOS-Chem $4^{\circ} \times 5^{\circ}$ simulation, as shown in Fig. 2. Reducing potential errors from this mismatch in spatial scale requires the use of a priori information at spatial resolutions equivalent to, or higher than, the satellite footprint. Hence, in addition to the coarse $4^{\circ} \times 5^{\circ}$ simulation, GEOS-Chem is used to generate $\mathrm{HCHO}$ and AOD profiles globally at $2^{\circ} \times 2.5^{\circ}$ and for tropical South America at $0.5^{\circ} \times 0.667^{\circ}$ to assess their subsequent impact on corresponding HCHO AMFs.

Figure 2 shows significant differences in model $\mathrm{HCHO}$ column distributions over the Amazon region, between the various GEOS-Chem simulations. The GEOS-Chem nested grid model displays more of the finer detail, compared to the medium and coarse grids, owing to its higher horizontal resolution. The vertical distribution of model tracer species is also affected by GEOS-Chem's resolution configuration. Figure 3 shows model vertical profiles of $\mathrm{HCHO}$, alongside black and organic carbon AOD, simulated by GEOS-Chem at $4^{\circ} \times 5^{\circ}$ and $0.5^{\circ} \times 0.667^{\circ}$ resolutions. Clear differences in vertical structure are evident for HCHO and AOD between the two simulations, both within and above the boundary layer, reflecting the simulated changes in tropospheric chemistry due to different emissions and meteorology. For comparison, the monthly mean $4^{\circ} \times 5^{\circ}$ profiles used in the AMF LUT (Sect. 4.4) are also shown in Fig. 3, to illustrate the differences in vertical profiles compared to the daily output. The vertical distribution is critical in the AMFs calculation, as it influences the measurement sensitivity at a given altitude, via Eq. (2).

Figure 4 shows the spatial maps and histograms of the AMF percentage difference (relative to the default case) resulting from use of $\mathrm{HCHO}$ and AOD profiles from the high- 

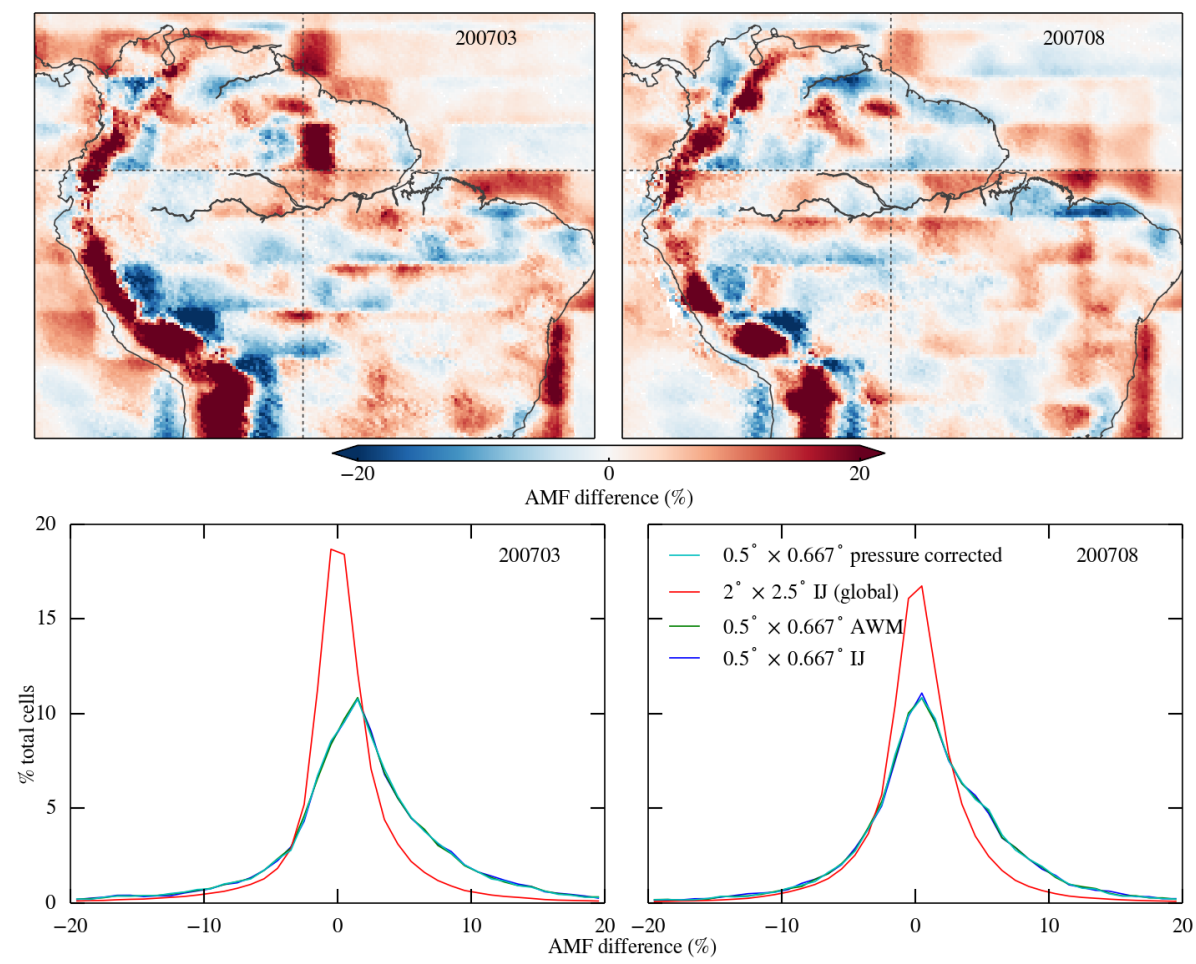

Figure 4. Top row: spatial maps of monthly mean AMF differences for March and August 2007, relative to the default UoL AMF algorithm, resulting from the use of atmospheric profiles from the GEOS-Chem $0.5^{\circ} \times 0.67^{\circ}$ nested grid simulation, as outlined in Sect. 5.2. The AMFs are gridded on to a $0.25^{\circ} \times 0.25^{\circ}$ grid using observations with cloud fractions $<40 \%$. Bottom row: the corresponding histograms of the AMF differences for these two months are shown in blue. The histogram of global AMF differences arising from the use of atmospheric profiles from GEOS-Chem's $2^{\circ} \times 2.5^{\circ}$ simulation is shown in red. Also shown are histograms resulting from the area-weighting (green) and surface pressure correction (aqua) of the $0.5^{\circ} \times 0.67^{\circ}$ nested grid profiles, as discussed in Sects. 5.3 and 5.4 respectively. Note the closeness of lines detailing derivatives of the high-resolution $0.5^{\circ} \times 0.67^{\circ}$ grids.

resolution GEOS-Chem Amazon nested grid. AMFs can vary $\pm 20 \%$, with the largest changes typically found at the edges of coarse grid cells, along coastlines, and over mountainous regions, reflecting the ability of the nested model to better capture HCHO spatial variations over changing terrain. Similarly, AMF differences arising from the use of global $2^{\circ} \times 2.5^{\circ}$ profile data are slightly smaller, typically $\pm 10 \%$, with the biggest differences again over grid cell boundaries, coastlines and mountain regions. The magnitude of the AMF differences therefore increases with higher spatial model resolution. Hence to reduce unnecessary errors, data users focusing on regional studies should aim to recalculate AMFs using profile information which can resolve the spatial characteristics of their target domain.

\subsection{Impact of footprint area weighting}

A pure grid cell selection algorithm (hereafter referred to as "IJ"), which uses the observation centre coordinates to select the most appropriate a priori data, can lead to representation errors by not accounting for satellite pixels that overlap multiple model grid cells. To overcome this issue an area-weighted mean value (AWM) for each scan is calculated based on the areal proportions of GEOS-Chem grid cells underlying the satellite footprint. The area-weighted values of all gridded AMF inputs (surface pressure and model profiles) are computed using a tessellation algorithm originally developed by Spurr (2003) for GOME and SCIAMACHY operational processing. Before calculation of average areaweighted profile quantities, all model profiles within the satellite footprint are first interpolated onto a common vertical pressure grid, based on the area-weighted surface pressure, to account for pressure level differences between neighbouring GEOS-Chem grid cells. The total AOD is preserved by scaling the final profile accordingly.

To evaluate this method the area-weighting technique was first applied to all three GEOS-Chem model simulations independently, and compared to the corresponding results when the IJ method is applied to the same model grid resolution. In all three cases, use of AWM model profiles changes the AMFs by about $\pm 2.5 \%$ for about $85-95 \%$ of locations, i.e. only a small difference overall (see also Fig. S2). If AMFs, calculated using AWM model profiles from GEOSChem's nested grid $0.5^{\circ} \times 0.667^{\circ}$ simulation, are then compared to AMFs from the default UoL algorithm, the effect 


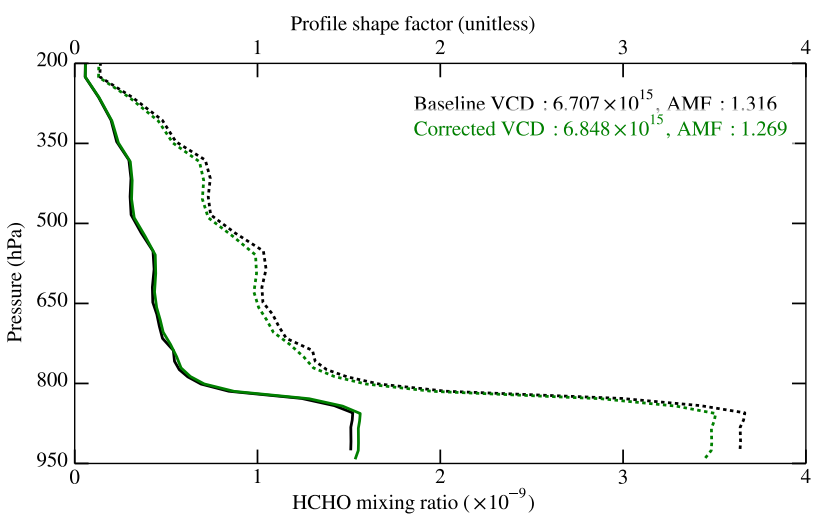

Figure 5. Effect of the vertical profile pressure correction (Sect. 5.4 of main text) for a scan over the Ecuadorian Andes $\left(78^{\circ} \mathrm{W} 1^{\circ} \mathrm{N}\right)$; with $\mathrm{HCHO}$ mixing ratios taken from a GEOS-Chem $4^{\circ} \times 5^{\circ}$ simulation (solid line) along the bottom $x$ axis and corresponding calculated shape factor $S$ (dotted line) on the top axis. The corrected model HCHO profile is shifted upwards and reduced in magnitude as a result of the lower surface pressure value on which to base the profile. Scattering weights are accordingly reduced, acting to reduce the AMF for this scan, and subsequently increase the calculated HCHO VCD.

of the AWM is also small and less than the effect of using the nested grid profiles alone, as shown by the green and blue lines, respectively, in the histograms of Fig. 4. Hence for GOME-2, the effect on the AMFs from using higher-resolution model data is greater than effects from area-weighting model quantities. This is also true globally when both IJ and AWM model profiles from GEOS-Chem's $2^{\circ} \times 2.5^{\circ}$ profile are compared to the default UoL algorithm (not shown). Nevertheless, the area-weighting of model profiles still represents a small but important correction for those observations straddling multiple model grid cells.

\subsection{Impact of surface pressure correction}

Accurate surface pressure values are a critical component in defining the trace gas vertical distribution. Zhou et al. (2009) presented a modification to regional $\mathrm{NO}_{2} \mathrm{AMF}$ calculations, to mitigate for terrain bias in mountainous regions due to inadequate topography representation. Accordingly, this terrain pressure correction is also applied here for HCHO. Following the terminology of Zhou et al. (2009), the $0.0083^{\circ} \times 0.0083^{\circ}$ GMTED2010 Digital Elevation Model (DEM) (Danielson and Gesch, 2011), is used to calculate $h_{\text {eff }}$, an area-weighted effective terrain height for each GOME-2 observation. Similarly, corresponding areaweighted model values of surface temperature $\left(T_{\text {surf }}\right)$, original surface pressure $\left(p_{\text {CTM }}\right)$ and CTM terrain height $\left(h_{\text {CTM }}\right)$ are also computed for each scan. To perform the correction, an effective surface pressure $p_{\text {eff }}$ is first derived:

$p_{\text {eff }}=p_{\text {CTM }} \times\left(\frac{T_{\text {surf }}}{T_{\text {surf }}+\Gamma \times\left(h_{\mathrm{CTM}}-h_{\text {eff }}\right)}\right)^{-g / r \Gamma}$, with $\Gamma$ the adiabatic lapse rate of $6.5 \mathrm{~K} \mathrm{~km}^{-1}, g$ as gravitational acceleration at $9.8 \mathrm{~m} \mathrm{~s}^{-2}$, and $r$ dry air gas constant of $287 \mathrm{~J} \mathrm{~kg}^{-1} \mathrm{~K}^{-1}$. From this, the tops and bottoms of the model pressure layers $l$ are defined for $p_{\text {eff }}$ and $p_{\mathrm{CTM}}$, using GEOS-5's eta $(\eta)$ vertical coordinate:

$$
\begin{aligned}
& p_{\mathrm{CTM}_{\mathrm{b}}}(l)=\eta_{A}(l)+p_{\mathrm{CTM}} \times \eta_{B}(l) \\
& p_{\mathrm{CTM}_{\mathrm{t}}}(l)=\eta_{A}(l+1)+p_{\mathrm{CTM}} \times \eta_{B}(l+1) \\
& p_{\mathrm{eff}_{\mathrm{b}}}(l)=\eta_{A}(l)+p_{\text {eff }} \times \eta_{B}(l) \\
& p_{\mathrm{eff}_{\mathrm{t}}}(l)=\eta_{A}(l+1)+p_{\text {eff }} \times \eta_{B}(l+1),
\end{aligned}
$$

where the $\eta_{A}$ and $\eta_{B}$ are the GEOS-5 coefficients that define the pressure levels. A scaling factor, to conserve mixing ratios when interpolating to the new pressure grid, is calculated from

$p_{\text {eff }_{\text {scl }}}(l)=\frac{p_{\text {eff }_{\mathrm{b}}}(l)-p_{\text {eff }_{\mathrm{t}}(l)}}{p_{\mathrm{CTM}_{\mathrm{b}}}(l)-p_{\mathrm{CTM}_{\mathrm{t}}}(l)}$.

Model HCHO profiles are then transferred to the new $p_{\text {eff }}$ grid, and scaled with $p_{\text {eff }_{\text {scl }}}$; AOD profiles are also interpolated to the new grid and the total column AODs preserved. Figure 5 details an example $\mathrm{HCHO}$ profile before, and after, the application of the pressure correction, with the shape and amount of the vertical profile changing as a function of the scaling value derived for the new pressure grid; in this instance the AMF decreases by about $4 \%$. To illustrate the effect of the pressure correction on a scan by scan basis, individual GOME-2 orbits over the Amazon are presented in Fig. 6. To isolate the effect of the pressure correction, AMFs calculated with area-weighted GEOS-Chem inputs from the default algorithm are shown in the top left plot. For these orbits, adjusting the coarse-resolution $4^{\circ} \times 5^{\circ}$ surface pressure grids with the high-resolution GMTED surface elevation data produces AMF differences of up to $\pm 5 \%$, mostly over areas of rapidly changing terrain (e.g. over the Andes mountains). However, when surface pressure correction is applied to the GEOS-Chem $0.5^{\circ} \times 0.667^{\circ}$ nested grid profiles, the effect is smaller as the GEOS-5 surface pressures more accurately represent the surface topography. This is confirmed by the histograms shown in Fig. 4, which reveals the impact area-weighting (green line) and the subsequent pressure correction (aqua line) are small, in comparison to the effect of using the $0.5^{\circ} \times 0.667^{\circ}$ nested grid profiles alone (blue line).

\subsection{Impact of new GOME-2 surface albedo product}

The baseline UoL AMF algorithm uses the surface reflectance maps from the Herman and Celarier (1997) database. Choice of surface reflectance data is critical since it can cause $20 \%$ changes in retrieved tropospheric $\mathrm{HCHO}$ and $\mathrm{NO}_{2}$ columns (Zhou et al., 2010; Barkley et al., 2012). Bi-directional distribution function (BRDF) effects associated with the surface reflectance are less than $<5 \%$ for $\mathrm{NO}_{2}$ (Zhou et al., 2010), but unfortunately for HCHO cannot be assessed owing to the lack of a BRDF product at relevant 

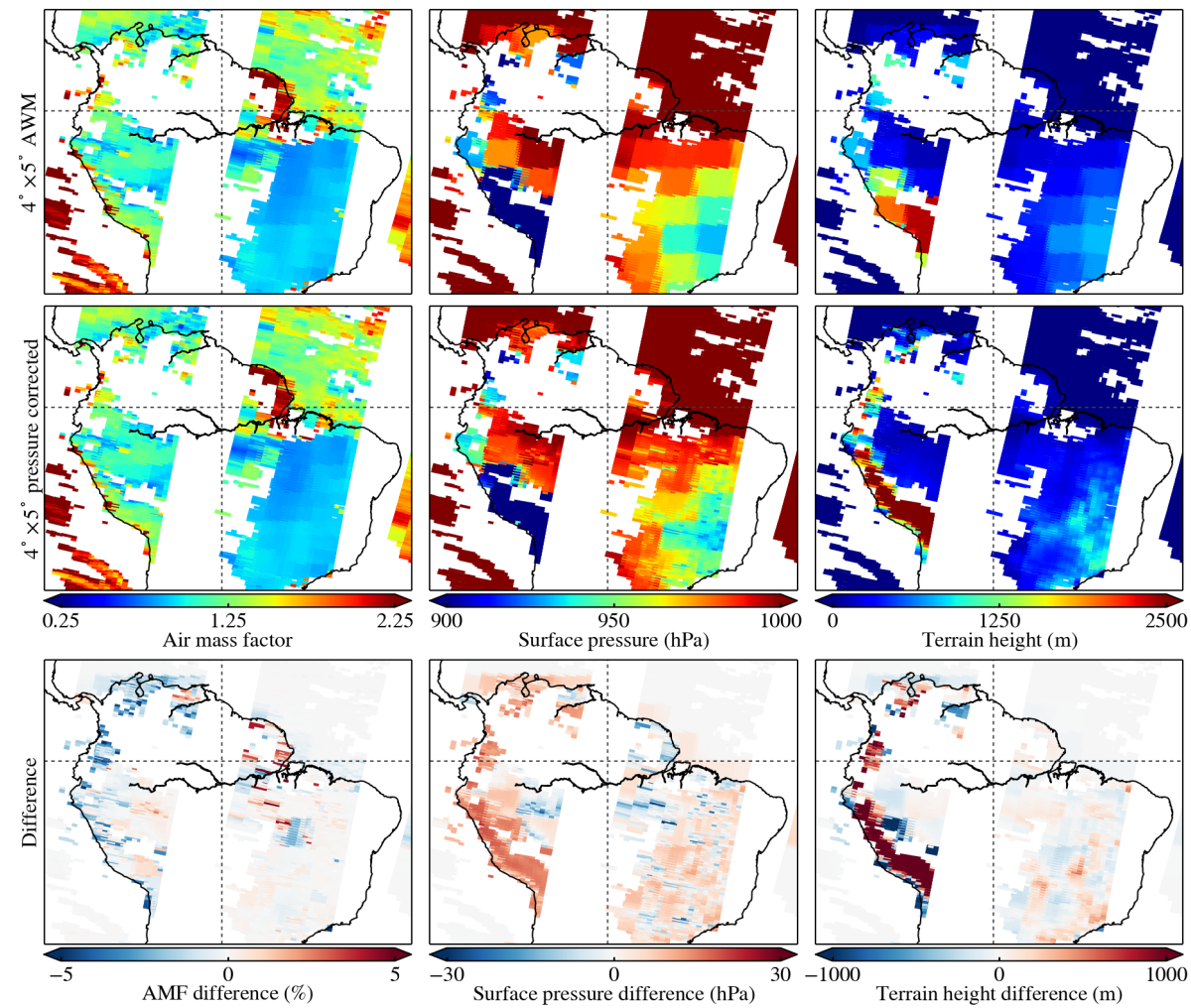

Figure 6. GOME-2 orbital tracks over the Amazon showing the effect of the Zhou et al. (2009) pressure correction (Sect. 5.4) against a fully area-weighted set of GEOS-Chem $4^{\circ} \times 5^{\circ}$ inputs (Sect. 5.3). Left to right: the first two rows (area weighted mean only inputs, and pressure-corrected AWM inputs on the second) show AMF, model surface pressure and terrain height; the bottom row details difference between these parameters for both cases. Differences between the two tests are exclusively due to the pressure correction alone. As such, the correction is most noticeable over mountainous terrain, causing AMF differences of about $\pm 5 \%$.

wavelengths. Given the stronger Rayleigh scattering that occurs at UV wavelengths, BRDF effects on the AMF will likely be smaller for $\mathrm{HCHO}$ than found for $\mathrm{NO}_{2}$.

To improve the UoL AMF algorithm the surface reflectance is upgraded to the GOME- $21.0^{\circ} \times 1.0^{\circ}$ database generated by Tilstra et al. (2014a), using the mode LER data at $340 \mathrm{~nm}$. Furthermore, daily changes in surface reflectance are accounted for using linear interpolation between months, following the approach of Boersma et al. (2011b), and with the area-weighting procedure described in Sect. 5.3 also applied.

Compared with the TOMS data, the GOME-2 mode LER reflectances are generally higher in most regions (see Figs. S3 and S4 in the Supplement). The overall difference between GOME-2 and TOMS is most likely due to differences in the radiometric calibration of the two instruments, but on a regional scale also the different orbital characteristics of each instrument and their respective treatment of clouds may play a role. A higher albedo results in a higher AMF owing to an increased measurement sensitivity as more photons are reflected. Consequently, AMF differences reflect these albedo changes, as shown in Fig. 7. Relative to the default UoL AMF algorithm, about 80-90\% of locations show an AMF increase of between 0 and $20 \%$, and about $<10 \%$ of locations show a decreases of up to $10 \%$. The overall median AMF difference is about $4 \%$ for March and August. These statistics are consistent if the GOME- 2 min LER is used instead of the mode LER, although localised spatial differences occur and the $1 \sigma$ width of fitted exponential probability density functions to the histograms increases from $2.7 \%$ (min LER) to $4.1 \%$ (mode LER) in August; in March the $1 \sigma$ value is unchanged.

By comparison, if the OMI mode LER at $342 \mathrm{~nm}$, which is available at $0.5^{\circ} \times 0.5^{\circ}$ resolution (Kleipool et al., 2008), is used in the UoL AMF algorithm in the same manner, the AMF differences are slightly less positively skewed, as shown in Fig. S5. Compared with the TOMS data, ocean albedos are generally higher with the OMI product, whilst over land, albedos are also generally higher, with some exceptions including high northern latitudes, and much of the boreal landmass in March (Fig. S3). Figure S4 shows that relative to the default UoL AMF algorithm, about $65-80 \%$ of locations show an AMF increase of up to $10 \%$, and about $15-25 \%$ of locations show a decrease of up to $10 \%$. The median AMF difference is about $2 \%$. Use of the OMI $342 \mathrm{~nm}$ 

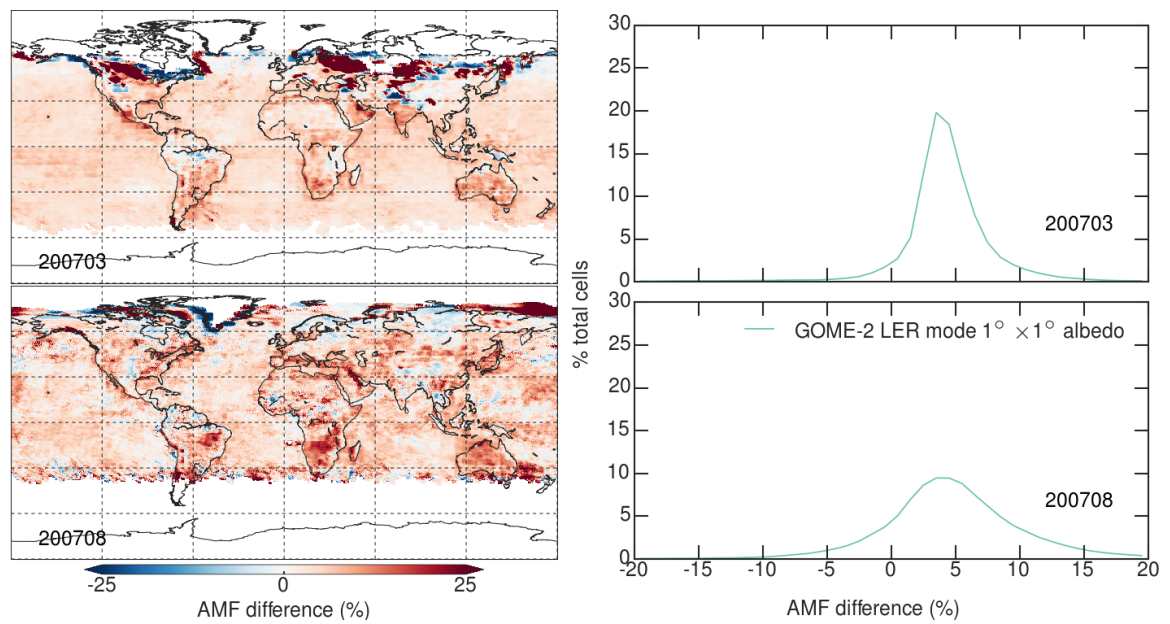

Figure 7. Left: spatial maps of the AMF differences resulting from the use of the temporally interpolated and area-weighted GOME-2 $1^{\circ} \times 1^{\circ} 340 \mathrm{~nm}$ mode LER (Tilstra et al., 2014), as discussed in Sect. 5, relative to the default UoL AMF algorithm i.e. $100 \% \times($ new AMF - baseline AMF)/naseline AMF. The AMFs are gridded on to $0.25^{\circ} \times 0.25^{\circ}$ using observations with cloud fractions $\leq 40 \%$. Right: corresponding histograms of the AMF differences.

min LER yields similar changes in the AMF, with median differences of about $1 \%$.

\subsection{Impact of GOME-2 cross sections}

The baseline AMF implementation generates scattering weights with $\mathrm{HCHO}$ using absorption spectra based on Cantrell et al. (1990). This is improved on by passing the HCHO (Meller and Moortgat, 2000) and ozone (Malicet et al., 1995) cross sections from the slant column fitting of the GOME-2 retrieval, convolved to the current orbit's asymmetric slit function, additionally allowing for the time-dependent slit function degradation throughout the instrument's lifetime (e.g. Cai et al., 2012; Dikty and Richter, 2012). Furthermore, the $\mathrm{HCHO}$ and ozone cross sections are adjusted to the local temperature profile, via cited temperature coefficients. However, the result of this algorithm update is minor, causing a fairly uniform global decrease in AMFs of between 0 and $2 \%$.

\subsection{Impact of TOMS ozone climatology}

In the baseline UoL AMF algorithm, $\mathrm{O}_{3}$ vertical mixing ratios are fixed to a single profile representing the US standard summertime atmosphere, thus any major $\mathrm{O}_{3}$ spatial and temporal variations are ignored in the AMF computation. Using a fixed $\mathrm{O}_{3}$ profile is therefore likely to introduce errors through incorrect scattering weight values, particularly significant for weak absorbers such as HCHO. To overcome this issue, the fixed $\mathrm{US}_{3}$ profile is replaced by a climatology derived from TOMS version $8 \mathrm{O}_{3}$ (Bhartia, 2002) data, as applied in the SCIATRAN v2.2 radiative transfer model (Rozanov et al., 2005). The TOMS v8 climatology provides monthly $\mathrm{O}_{3}$ VMRs in eighteen $10^{\circ}$ latitude bands for 61 atmospheric levels. To account for concurrent $\mathrm{O}_{3}$ variability, each selected TOMS v8 profile is interpolated onto the pressure grid based on the AWM surface pressure, and then scaled to coincident GOME- $2 \mathrm{O}_{3}$ total column measurements, provided operationally by DLR in the framework of the EUMETSAT/O3M-SAF project (Loyola et al., 2011). Note that a similar scaling of the US ozone profile was also performed by Lee et al. (2009) in the computation of OMI $\mathrm{SO}_{2}$ AMFs.

Results of the ozone profile substitutions are presented in Fig. S6, which shows that whilst the magnitude of the AMF differences are small, mostly within $\pm 2 \%$, the variation is geographically widespread. The most notable changes occur over regions of high surface elevation $(>1500 \mathrm{~m})$ where divergence between the US standard atmosphere and TOMS v8 ozone profiles, relative to the $\mathrm{HCHO}$ profile peak, are most pronounced.

\subsection{Combined effect of all AMF updates}

To produce an improved air mass factor calculation the updates presented are combined in a new UoL AMF algorithm, as summarised in Table 3. In future, global processing of the GOME-2 HCHO columns (as here) will rely on using GEOSChem model data at $2^{\circ} \times 2.5^{\circ}$ resolution, whereas studies focusing on tropical South America will utilise output from the Amazon nested grid simulation. Figure 8 shows the differences of the new AMF algorithm against the initial baseline implementation. On a single Intel Xeon X5550 running at $2.67 \mathrm{GHz}$, per-orbit processing time for the AMF calculations including all algorithm modifications is between 15 and 20 min (increased from 7 to 8 min per orbit for the baseline method), reflecting extra time spent applying pixel tessellation routines to input grids. 
Table 3. Summary of the baseline and updated UoL AMF algorithm.

\begin{tabular}{|c|c|c|}
\hline & Baseline AMF algorithm & Updated AMF algorithm \\
\hline A priori profile & $\begin{array}{l}\text { GEOS-Chem daily profiles } \\
\text { - selected using observation centre coordinates }\end{array}$ & $\begin{array}{l}\text { GEOS-Chem daily profiles } \\
\text { - area-weighted mean for observation footprint }\end{array}$ \\
\hline Surface pressure & GEOS-Chem $\left(4 \times 5^{\circ}\right)$ & $\begin{array}{l}\text { GEOS-Chem }\left(2 \times 2.5^{\circ}\right) \\
\text { - adjusted by area-weighted mean elevation }\end{array}$ \\
\hline Surface elevation & NA & GMTED2010 $\left(0.0083 \times 0.0083^{\circ}\right)$ \\
\hline LIDORT cross sections & Fixed OMI cross section & Orbit-specific GOME-2 \\
\hline Aerosol correction & GEOS-Chem monthly mean AOD profiles & $\begin{array}{l}\text { GEOS-Chem daily AOD profiles* } \\
\text { - area-weighted mean for observation footprint }\end{array}$ \\
\hline
\end{tabular}

*Algorithm employs optional flag to switch between explicit versus implicit (AODs $=0.0$ ) aerosol correction (see discussion in Sect. 6.2)
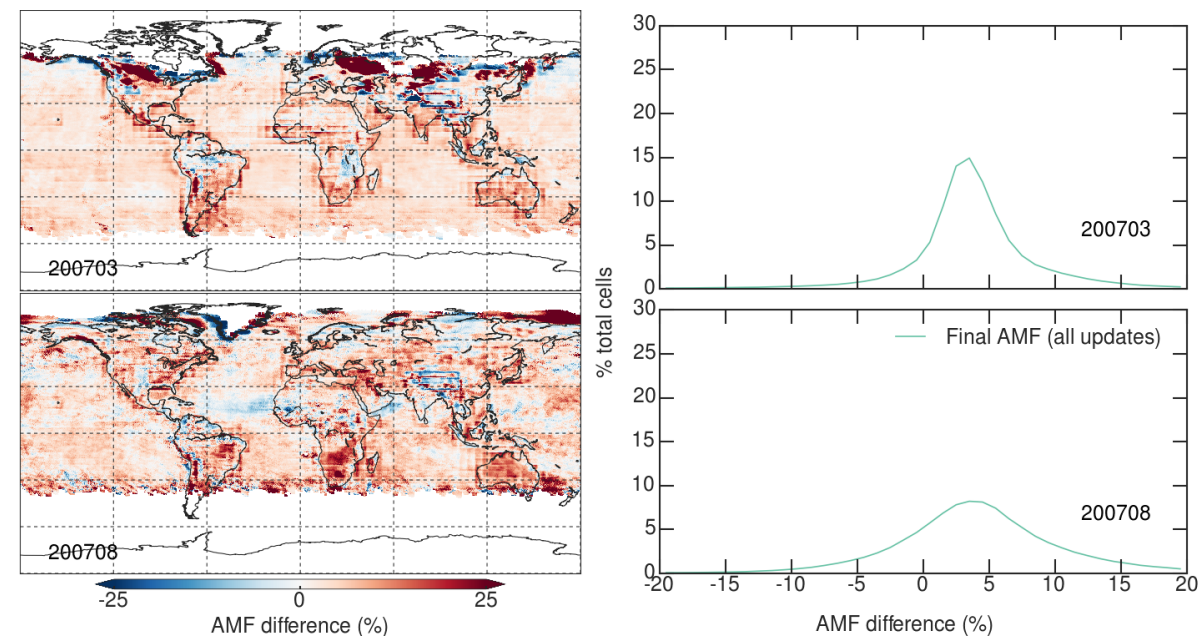

Figure 8. Left: spatial maps of the AMF differences resulting from the application of all AMF updates, as discussed in Sect. 5.8, relative to the default UoL AMF baseline algorithm (Sect. 4.3), i.e. $100 \% \times($ final AMF - baseline AMF)/baseline AMF. The AMFs are gridded to a $0.25^{\circ} \times 0.25^{\circ}$ using observations with cloud fractions $<40 \%$. Right: corresponding histograms of the AMF differences.

Typically differences between the original IJ algorithm and the updated AMF calculations are of the order of $\pm 20 \%$, although the histogram of the AMF differences shown in Fig. 8 is positively skewed. Overall, the median AMF differences are about $4 \%$, and over $70 \%$ of locations now have an AMF of 0-20\% larger than produced from the baseline algorithm. This increase is driven by the use of the new GOME2 surface reflectance product. Other significant changes occur over mountain regions, coastlines and the grid cell outlines of the GEOS-Chem $2^{\circ} \times 2.5^{\circ}$ and $4^{\circ} \times 5^{\circ}$ horizontal grids. Cancellation of opposing effects from individual algorithm changes mitigates the magnitude of the overall difference. Besides on average increasing the AMFs, the overall impact of the algorithm updates is therefore to mainly improve the tropospheric vertical column retrievals over regions with rapidly changing surface elevation and terrain properties. AMFs from the updated UoL algorithm are now 0.643.82 over land and $0.73-4.64$ over the oceans. Interestingly, in August 2007 there is a significant reduction in the AMFs over the mid-Atlantic, and over the Arabian sea, just south of 


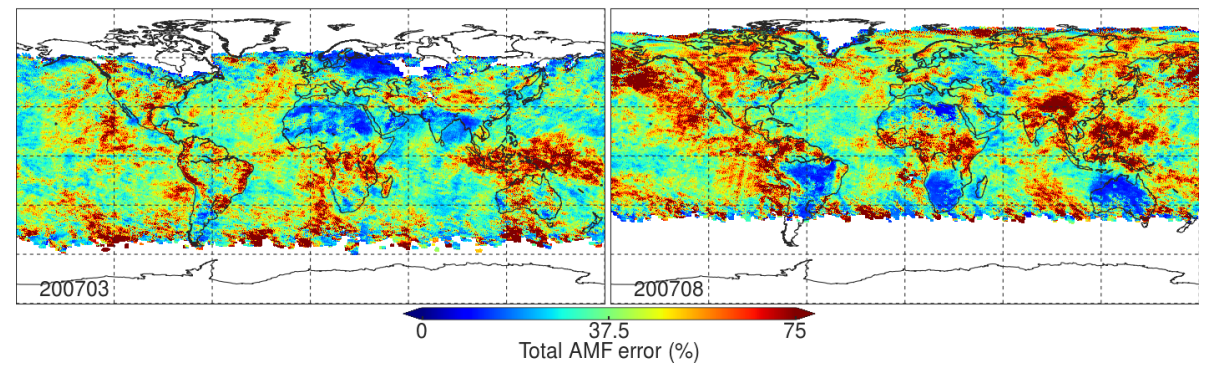

Figure 9. Monthly mean GOME-2 total AMF errors for March (left) and August (right) 2007 calculated using Eq. (7). The AMF errors are gridded on to a $0.25^{\circ} \times 0.25^{\circ}$ grid using observations with cloud fractions $<40 \%$.

the Yemen and Oman coastlines. These features are spatially coincident with elevated dust AODs from GEOS-Chem, reflecting the simulated aerosol field sensitivity to the model's spatial resolution, and its subsequent effect on the AMF. If the aerosol are not included in the AMF algorithm (i.e. the AOD is set to zero), then the decrease in the AMFs over these regions is not observed (see Sect. 6.2).

\section{AMF error assessment}

Any AMF algorithm should properly characterise its error. Individual AMF error estimates are valuable as they provided a more robust error characterisation of the $\mathrm{HCHO}$ vertical columns; this allows correct observational uncertainty weighting when grid averaging and to properly calculate the errors of inferred top-down VOC emissions. Following Boersma et al. (2004) and De Smedt et al. (2008), the AMF total error $\left(\sigma_{\mathrm{AMF}}\right)$ may be expressed as

$$
\begin{aligned}
\sigma_{\mathrm{AMF}}^{2} & =\left(\frac{\partial \mathrm{AMF}}{\partial A_{\mathrm{s}}} \sigma_{A_{\mathrm{s}}}\right)^{2}+\left(\frac{\partial \mathrm{AMF}}{\partial \mathrm{CF}} \sigma_{\mathrm{CF}}\right)^{2} \\
& +\left(\frac{\partial \mathrm{AMF}}{\partial \mathrm{CTP}} \sigma_{\mathrm{CTP}}\right)^{2}+\left(\frac{\partial \mathrm{AMF}}{\partial S} \sigma_{\mathrm{S}}\right)^{2},
\end{aligned}
$$

where $\sigma_{A_{\mathrm{s}}}, \sigma_{\mathrm{CF}}, \sigma_{\mathrm{CTP}}$ and $\sigma_{\mathrm{S}}$ are the uncertainties associated with the surface albedo, cloud fraction, cloud-top pressure and the HCHO shape profile, and the partial derivatives indicate the local AMF sensitivity with respect to each parameter. For the GOME-2 data (2007-2010) the AMF errors are explicitly calculated for each observation (using the updated algorithm) through assigning appropriate uncertainties for $\sigma_{A_{\mathrm{s}}}$, $\sigma_{\mathrm{CF}}, \sigma_{\mathrm{CTP}}$ and $\sigma_{\mathrm{S}}$, and then by applying these uncertainties to determine the local AMF sensitivity, i.e. by generating partial derivatives of the radiance fields with respect to these sources of model error using LIDORT. Systematic values of $\sigma_{\mathrm{CF}}=0.05$ and $\sigma_{\mathrm{CTP}}=60 \mathrm{hPa}$ are used for cloud parameter uncertainties (Wang et al., 2008). The GOME-2 reflectance product has an associated uncertainty for each grid cell which is used for $\sigma_{A_{\mathrm{s}}}$ (Tilstra et al., 2014a). Figure S4 shows the geographical distribution of $\sigma_{A_{\mathrm{s}}}$ for March and August; uncertainties are typically largest at high latitudes and also over the Sahara. Based on comparisons to TOMS, GOME-1 and OMI LER data, the GOME-2 surface LER product is estimated to be accurate within 0.01 for the UV wavelength bands (Tilstra et al., 2014b). Quantification of the profile uncertainty $\sigma_{\mathrm{S}}$ is difficult to assess, since the $\mathrm{HCHO}$ vertical distribution is influenced by many complex processes (e.g. transport, chemistry and boundary layer height). Hence in the case of the HCHO profile shape, the error and local sensitivity are estimated using a poor man's approach by perturbing the HCHO profiles below and two model layers above the simulated $\mathrm{HCHO}$ peak by $+25 \%$, whilst layers above these are decreased by $-25 \%$. The $25 \%$ uncertainty is based on the study of Barkley et al. (2011), who compared various GEOS-Chem simulations of HCHO to aircraft observations over Guyana and surrounding areas. These profile uncertainties are higher than those determined by Millet et al. (2006) for the US, reflecting significant modelling errors for tropical latitudes (i.e. high VOC emission and low $\mathrm{NO}_{x}$ conditions). Modifying the $\mathrm{HCHO}$ profile in this way also provides a partial assessment of AMF uncertainties due to the presence of aerosols and clouds, since their relative vertical distribution has changed. However, without precise information on the aerosol distribution and optical properties it is extremely difficult to accurately quantify aerosol-induced errors; simply adjusting the GEOS-Chem aerosol profiles only provides a limited insight into this error source (e.g. Barkley et al., 2012).

Figures 9 and 10 show total and individual component errors respectively, revealing that AMF uncertainty varies considerably both in magnitude and distribution. The greatest source of AMF uncertainty is associated with the HCHO profile shape, with median errors of the order of $50 \%$. HCHO profile errors are particularly large where low-lying cloud occurs, e.g. off the west coast of North and South America in August, owing to cloud albedo and shielding effects. In such cases the large AMF errors are more attributable to the sensitivity of the $\mathrm{HCHO}$ vertical distribution relative to the cloud layer, rather than uncertainties in the HCHO profile shape alone. A further AMF calculation, in which the reverse $25 \%$ scaling to the a priori HCHO profile was also performed, resulted in similar but more widespread errors. Over regions 

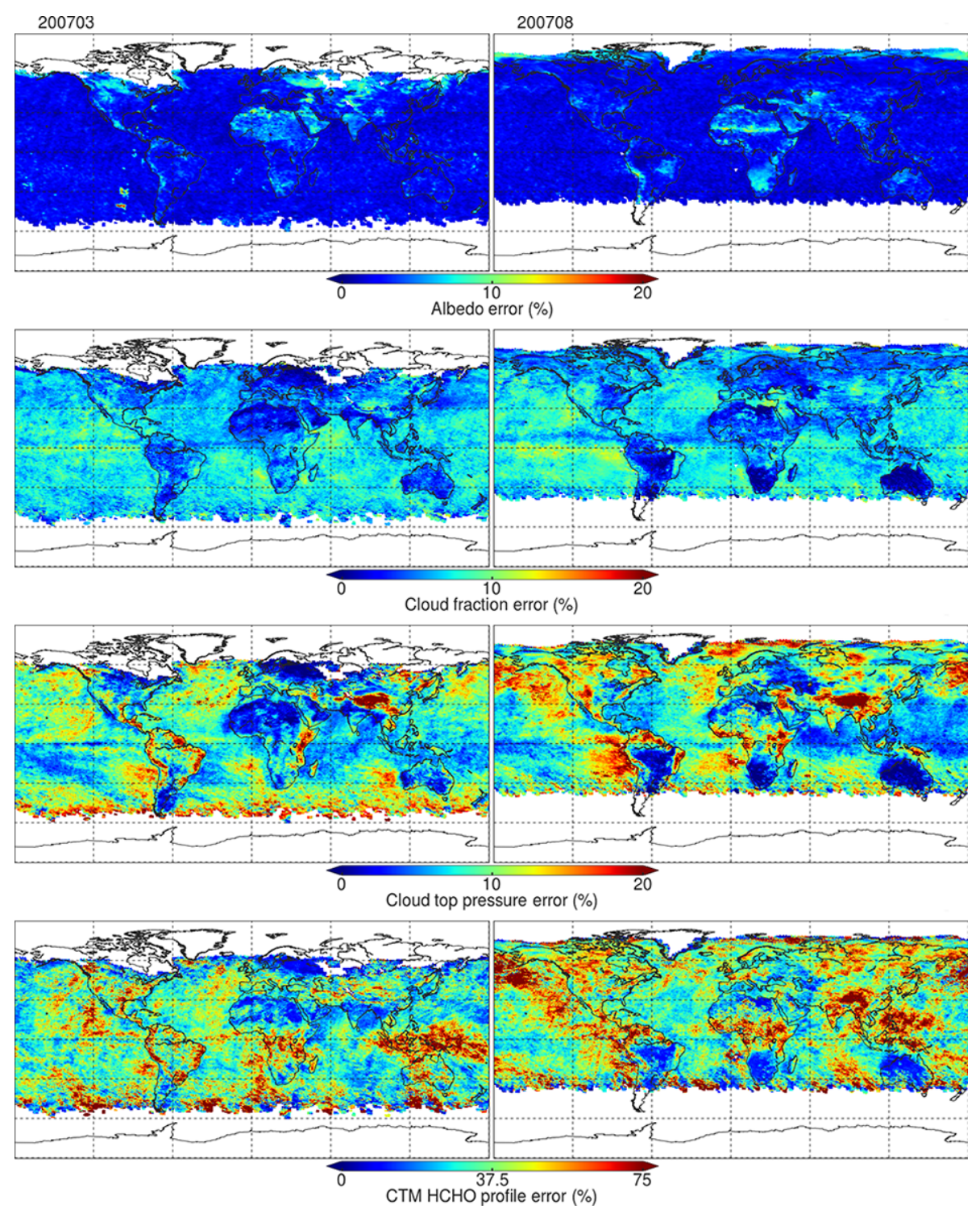

Figure 10. Monthly mean GOME-2 component albedo, cloud fraction, cloud-top pressure and CTM HCHO profile AMF errors for March (left) and August (right) 2007. Errors are gridded on to a $0.25^{\circ} \times 0.25^{\circ}$ grid using observations with cloud fractions $<40 \%$.

where model $\mathrm{HCHO}$ can be simulated reasonably well (e.g. over the US; Millet et al., 2006), it is likely that AMF uncertainties from the profile shape will be less. To account for this, a further calculation in which the HCHO profile was scaled in a similar manner by $10 \%$ was also conducted. The resulting median AMF error from the profile shape decreased to about $30-40 \%$. Thus for profile errors of $10-25 \%$, the likely AMF error will be 30-50\%, and will decrease accordingly as the accuracy of the $\mathrm{HCHO}$ profile is increased.

In comparison to the $\mathrm{HCHO}$ shape error, average uncertainties due to cloud-top pressure and cloud fraction are both about $10 \%$, whilst those associated the surface albedo are about $5 \%$. Median AMF total errors are therefore approximately $50-60 \%$, consistent with those found previously for the SCIAMACHY and OMI instruments by Barkley et al. (2012). However, for individual observations GOME-2 AMF errors can range from 5 to $600 \%$ depending on the immediate local conditions. If the $10 \%$ scaling is applied to the $\mathrm{HCHO}$ profile in the error calculation (instead of the default $25 \%$ ), then the median total AMF error drops to about 30-40\%.

The calculated AMF uncertainties for GOME- 2 presented here are slightly larger than those determined for GOME over the US by Millet et al. (2006), who found AMF biases in the range 16-24\% through comparison of measured and modelled AMFs. This is partly due to this work's global analysis which must take into account larger model uncertainties over tropical latitudes. However, Millet et al. (2006) found that clouds were the dominant source of error in the AMF 


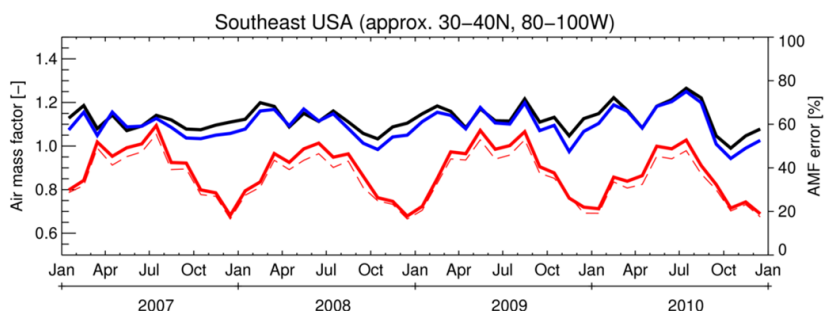

Tropical South America (approx. 24S-12N, 32-83W)

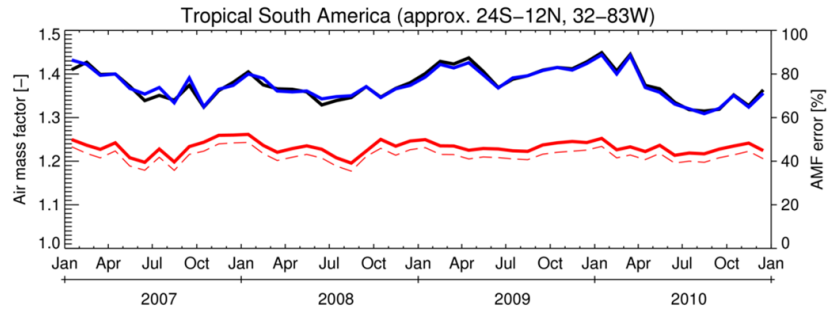

Figure 11. 2007-2010 time series over southeast USA (top) and tropical South America (bottom), showing monthly median AMFs calculated with and without aerosols (solid black and blue lines, respectively), and monthly median total AMF error (red solid line; calculated with aerosols present). The dashed red line shows the contribution to the total AMF error from uncertainty in the $\mathrm{HCHO}$ profile shape.

(10-21\% bias for cloud fractions ranging 30-60\%). Barkley et al. (2012) also confirmed that uncertainties in cloud fraction produced the biggest changes in SCIAMACHY and OMI AMFs over tropical South America. Hence to provide an alternative estimate of the errors due to cloud fraction and height, the change in the GOME-2 AMFs were calculated after systematically introducing errors of +0.1 in cloud fraction (after being cloud filtered using its original value) and $-60 \mathrm{hPa}$ in cloud-top height (as done similarly in Barkley et al., 2012). Figure S7 shows the change in AMFs for March 2007. Increasing the cloud fraction typically changes the AMFs by only $\pm 5 \%$ for over $95 \%$ of locations, whereas simulating a higher altitude cloud top (i.e. lower pressure) results in a median decrease of $5 \%$. Hence the impact of clouds on the GOME-2 appears relatively small, and hints towards requiring external validation with aircraft measurements to clarify its true magnitude.

An additional source of uncertainty is from the inconsistency of the different surface reflectivity and topography fields used in the GOME-2 AMF and FRESCO+ cloud algorithms. The latter uses the MERIS black-sky albedo (BSA) climatology (Popp et al., 2011) and the GTOPO30 topography data downgraded to $0.25^{\circ} \times 0.25^{\circ}$ (Wang et al., 2010) . Here the preferred option is to use the GOME- 2 surface reflectivity of Tilstra et al. (2014a), as it is consistent with the radiometric calibration of the instrument itself, and also the viewing geometry, time and wavelength of the GOME$2 \mathrm{HCHO}$ retrieval. It is theoretically possible to scale the MERIS BSA to $335 \mathrm{~nm}$ using the GOME-1 reflectances derived by Koelemeijer et al. (2003), using the approach out- lined in Boersma et al. (2004), although in reality it is acknowledged that the $335 \mathrm{~nm}$ reflectivity suffers significantly from instrument degradation (Koelemeijer et al., 2003). Nevertheless, MERIS $335 \mathrm{~nm}$ BSA maps were constructed via

$\operatorname{MERIS} A_{\mathrm{S}}(335 \mathrm{~nm})=\operatorname{MERIS} A_{\mathrm{S}}(412 \mathrm{~nm}) \times \frac{\operatorname{GOME} A_{\mathrm{S}}(335 \mathrm{~nm})}{\operatorname{GOME} A_{\mathrm{S}}(416 \mathrm{~nm})}$

and compared to the TOMS, OMI and GOME-2 reflectivities (all remapped to a $1^{\circ} \times 1^{\circ}$ grid). Overall, the GOME$2340 \mathrm{~nm}$ reflectivities agree marginally better with the scaled MERIS $335 \mathrm{~nm}$ BSA than the TOMS or OMI data (not shown), supporting their implementation in the AMF algorithm. Similarly, it is also preferable to use the higher resolution GMTED2010 topography, as it will give a more accurate surface pressure correction than the more coarse GTOPO30 topography. Hence a reprocessing of the FRESCO+ algorithm with the GOME-2 reflectance product and GMTED2010 is a priority to remove these inconsistencies.

Figure 11 shows the seasonal variability of the AMF and its error over two key regions: the southeast USA and tropical South America. In general, the monthly median AMFs show little variation over 2007-2010 for either region. For both regions, the total AMF error is dominated by the uncertainty associated with the a priori $\mathrm{HCHO}$ profiles. AMF errors over tropical South America also do not vary significantly, owing to copious biogenic emissions from the rainforest sustaining high levels of $\mathrm{HCHO}$ all year round. In contrast, the AMF errors over the southeast USA have a distinct seasonal pattern, with low AMF errors in winter when biogenic emissions and $\mathrm{HCHO}$ levels are a minimum, and high AMF errors in summer, when HCHO concentrations peak due to significant isoprene emissions (Palmer et al., 2006). Thus, any top-down estimates of isoprene emissions over North America are likely to be compromised by large AMF errors in the months of highest emissions. However, it is likely that HCHO profile errors over the southeast USA are in reality smaller than those calculated (which uses the globally applied $25 \% \mathrm{HCHO}$ profile scaling in the AMF error calculation), for the reasons discussed above. Examination of other regions (not shown), also confirms that any variance in the AMF errors is predominantly driven by biogenic emission seasonality influencing the $\mathrm{HCHO}$ profile shape (see e.g. Fig. S2 of Barkley et al., 2012).

\subsection{Aerosol effect on AMF errors}

In their assessment of HCHO AMF uncertainty, Barkley et al. (2012) conducted an extensive investigation into AMF sensitivity to AOD over the Amazon region for both SCIAMACHY and OMI HCHO AMFs. Their series of tests included calculating AMFs with no aerosol correction, arbitrary AOD scaling, and redistribution of black (BC) and organic (OC) carbon to various heights above the boundary layer dependent on AMF peak layer AOD residing in the 
boundary layer. Results from this work showed that $\mathrm{HCHO}$ AMFs were only significantly affected (in a range of 10 $50 \%$ ) when $\mathrm{BC}$ and $\mathrm{OC}$ were distributed high above the boundary layer to approximately $5 \mathrm{~km}-$ an extreme case of localised high aerosol loading.

For a basic indication of aerosol errors in this work we therefore include a brief investigation on aerosol effects on our GOME-2 AMFs. Testing of aerosol effects are limited to $\mathrm{BC}$ only, given the sensitivity of HCHO AMFs to the species found in Fu et al. (2007) and Barkley et al. (2012). To this end, scans were identified whose a priori GEOS-Chem BC AOD profile peaked within $2 \mathrm{~km}$ of the Earth's surface. In such cases, the BC AOD profile had its layer values increased between the surface and $5 \mathrm{~km}$ to its maximum value for that scan, and the local sensitivity (i.e. $\partial \mathrm{AMF} / \partial \mathrm{AOD}$ ) was then calculated using LIDORT. We calculate the new AMF error through inclusion of an extra term to Eq. (7), via

$\sigma_{\mathrm{AMF}}^{2}=\ldots+\left(\frac{\partial \mathrm{AMF}}{\partial \mathrm{AOD}} \sigma_{\mathrm{AOD}}\right)^{2}$

with $\sigma_{\mathrm{AOD}}$ assigned a value of $20 \%$. Scans with BC AOD profile peak above $2 \mathrm{~km}$ were assigned a default error of $20 \%$.

Estimated mean AMF error due to BC for the two tested months are plotted in Fig. S8, displaying maximum values in the range of 30-70\%, showing consistency with values reported in Barkley et al. (2012). Increased BC AMF error values exhibit a very similar spatial pattern to $\mathrm{HCHO}$ profile errors in Fig. 10, suggesting that the relative distribution of the two components is key for understanding the aerosol AMF error source. It should be noted that whilst aerosols may potentially create the largest uncertainty in the AMF calculation, their effects are often localised and that on continental scales, errors due to uncertainties in cloud parameters and the $\mathrm{HCHO}$ profile shape will likely be larger.

\subsection{Implicit aerosol correction}

The UoL baseline and updated AMF algorithms have focused on using an explicit aerosol correction through inclusion of aerosol optical depth profiles and properties in the LIDORT radiative transfer calculations. This is based on the optimistic assumption that the GEOS-Chem simulation of aerosols is correct, and that the presence of aerosol is not fully accounted for via the FRESCO+ cloud algorithm, through the independent pixel approximation (Martin et al., 2002). Despite evidence that the clouds can be effective for implicitly correcting for the presence of aerosols (Boersma et al., 2004, 2011a), a large number of studies have still opted for an explicit aerosol correction in their AMF calculations (see e.g. Martin et al., 2002; Palmer et al., 2006; Millet et al., 2006; Fu et al., 2007; Lee et al., 2009; Curci et al., 2010; Gonzi et al., 2011; Marais et al., 2012; Barkley et al., 2008, 2013). Aerosols complexly affect both the retrieval of cloud parameters and subsequent computation of tropo- spheric AMFs, depending on the aerosol type (scattering versus absorbing) and its relative vertical distribution to cloud height and the trace gas profile (see e.g. Figure 5 of Lin et al., 2014, and discussion therein). For example, Castellanos et al. (2015) showed that explicit aerosol corrections can overestimate OMI $\mathrm{NO}_{2}$ AMFs over South America by $20-40 \%$, for cloud-top pressures less than $800 \mathrm{hPa}$, but where cloud radiance fractions were less than 0.3 or effective cloud-top pressure greater than $800 \mathrm{hPa}$, the difference between tropospheric AMFs calculated using implicit and explicit aerosol parameters were about $6 \%$ for more than $70 \%$ of OMI pixels.

For these reasons, the updated UoL AMF algorithm was re-run with the explicit aerosol correction turned off (AODs set to zero). Figure 12 shows the AMF differences, relative to the updated UoL AMF algorithm with the explicit aerosol correction applied - i.e. (without AOD - with AOD)/(with AOD). For about $90 \%$ of locations the change in the AMFs is less than $\pm 5 \%$, but for a relatively small number of areas $(<1 \%)$ the changes in the AMF can be over $\pm 30 \%$. Including aerosol parameters from GEOS-Chem reduces the AMFs over dusty regions (e.g. the Sahara and tropical North Atlantic) and decreases AMFs over biomass burning regions (e.g. the southeast Amazon in August), results consistent with the study of Martin et al. (2003). Figures 11 and S9 show both sets of AMFs over 2007-2010 for four key regions: the southeast USA $(-2.5 \%$ median difference), the Amazon $(<-0.2 \%)$, central Africa $(+2.9 \%)$ and Europe $(<1 \%)$. In general, the AMF temporal variation, either with or without the inclusion of aerosol optical depths, is similar in all cases, and the differences generally small. Note that these findings also correlate with the implicit AMF aerosol correction sensitivity tests in Barkley et al. (2012), where aerosol corrections were shown to impart only a moderate effect on HCHO vertical columns over areas of large BVOC emissions $(<15 \%)$, with larger effects noted for regions and time periods containing significant quantities of desert dust, and biomass burning. Where these aerosol types and conditions are prevalent, the AMFs will likely be compromised, which may affect subsequent top-down VOC emission estimates. Clearly a much more detailed global study, following a similar approach to Castellanos et al. (2015), is warranted to resolve simultaneous aerosol and cloud effects on HCHO AMFs. This goal will be the key focus of future algorithm development. Until then, the implicit versus explicit aerosol correction will remain as an optional algorithm flag. This will allow assessment of the different AMFs, and subsequent $\mathrm{HCHO}$ vertical columns, against in situ validation data (e.g. MAX-DOAS measurements).

\section{Summary}

This work has presented and evaluated a new University of Leicester algorithm to compute HCHO AMFs for the GOME-2 instrument. The most novel aspects of the new al- 

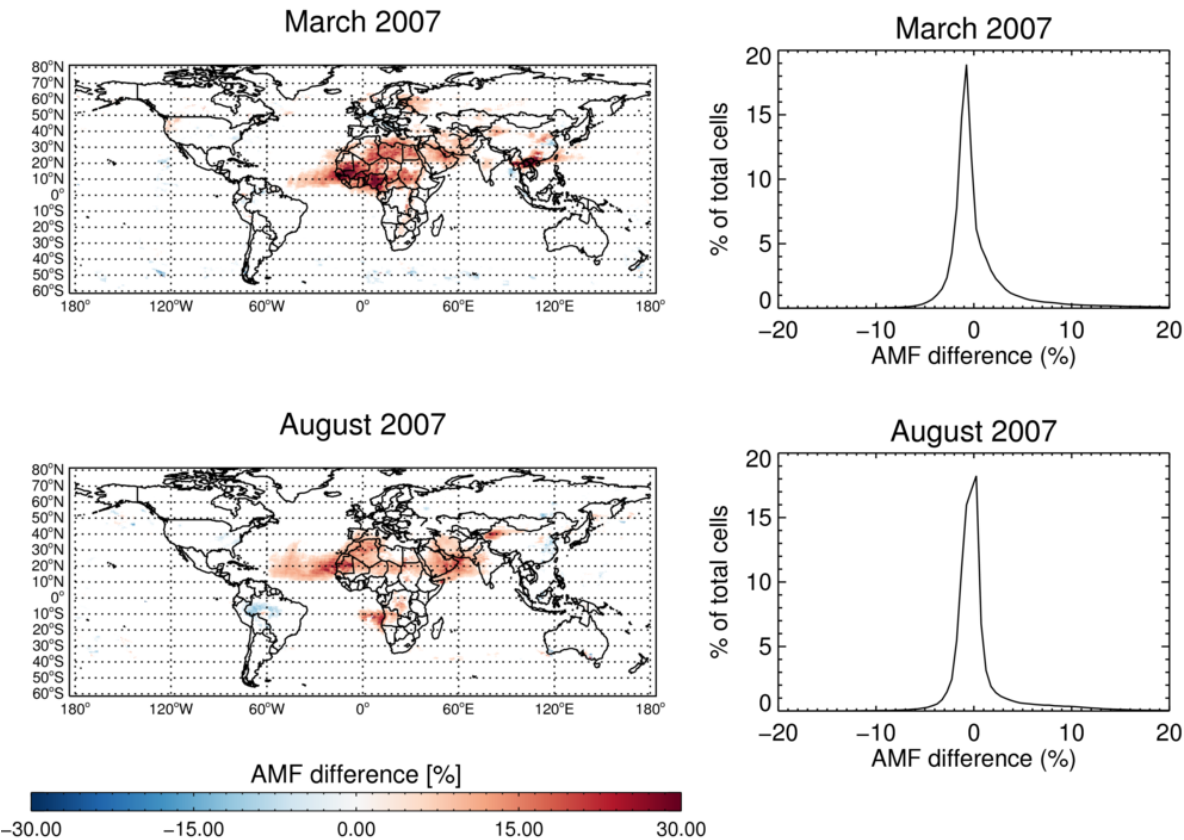

Figure 12. Left: spatial maps of the AMF differences which exceed $\pm 5 \%$, resulting from the implicit aerosol correction test using the final updated AMF algorithm, as discussed in Sect. 6.2, i.e. $100 \% \times(\mathrm{AMF}$ without AODs - AMF with AODs)/AMF with AODs. The AMFs are gridded to a $0.25^{\circ} \times 0.25^{\circ}$ using observations with cloud fractions $<40 \%$. Right: corresponding histograms of the AMF differences.

gorithm are the area weighting of improved a priori information over the satellite footprint, to more accurately represent the local surface conditions and atmospheric state, and the full radiative transfer calculation of the AMF and its error for each GOME-2 observation.

Compared to an earlier UoL AMF code, the new algorithm typically changes calculated AMFs by up to $\pm 20 \%$, but on average the AMFs are increased by $4 \%$, with over $70 \%$ of locations having an AMF of $0-20 \%$ larger than originally. This AMF increase largely comes from updating to the latest GOME-2 reflectance product. Other significant changes mostly occur over coastal and mountain regions, and the model cell boundaries of the GEOS-Chem horizontal grids. Another large impact on the AMFs arises from using $\mathrm{HCHO}$ profiles from a high-resolution GEOS-Chem $0.5^{\circ} \times 0.667^{\circ}$ nested grid simulation in preference to those from coarser global simulations. Furthermore, it is found that (a) the largest AMF error component is also associated with the $\mathrm{HCHO}$ profile shape and its vertical distribution relative to cloud height and aerosol profiles, and (b) seasonal variations in the total AMF error are driven by seasonal changes in the $\mathrm{HCHO}$ profile distribution. These results therefore highlight the critical importance of accurate and high-resolution profiles within the GOME-2 AMF calculation, or for that matter, any other $\mathrm{HCHO}$ retrieval. In addition, users of $\mathrm{HCHO}$ data products should be fully aware of seasonal shifts in the AMF error, and the likely impact on any inferred top-down emission estimates.
Ongoing efforts are being conducted to validate and develop a full-error analysis of the UoL GOME-2 HCHO tropospheric column product, to provide confidence in its use for inversion studies of surface VOC emissions. Further algorithm refinement to potentially improve retrievals in the presence of aerosols and over snow-covered surfaces are also being investigated.

\section{The Supplement related to this article is available online at doi:10.5194/amt-8-4055-2015-supplement.}

Acknowledgements. This work was supported by the UK National Centre for Earth Observation (NCEO) and the UK Natural Environment Research Council (NERC) (grants NE/G523763/1, NE/GE013810/2 and NE/D001471).

Edited by: J. Tamminen

\section{References}

Barkley, M. P., Palmer, P. I., Kuhn, U., Kesselmeier, J., Chance, K., Kurosu, T. P., Martin, R. V., Helmig, D., and Guenther, A.: Net ecosystem fluxes of isoprene over tropical South America inferred from GOME observations of HCHO columns, J. Geophys. Res., 113, D20304, doi:10.1029/2008JD009863, 2008. 
Barkley, M. P., Palmer, P. I., Ganzeveld, L., Arneth, A., Hagberg, D., Karl, T., Guenther, A., Paulot, F., Wennberg, P. O., Mao, J., Kurosu, T. P., Chance, K., Müller, J.-F., Smedt, I. D., Roozendael, M. V., Chen, D., Wang, Y., and Yantosca, R. M.: Can a "state of the art" chemistry transport model simulate Amazonian tropospheric chemistry?, J. Geophys. Res., 116, D16302, doi:10.1029/2011JD015893, 2011.

Barkley, M. P., Kurosu, T. P., Chance, K., Smedt, I. D., Roozendael, M. V., Arneth, A., Hagberg, D., and Guenther, A.: Assessing sources of uncertainty in formaldehyde air-mass factors over tropical South America: implications for top-down isoprene emission estimates, J. Geophys. Res., 117, D13304, doi:10.1029/2011JD016827, 2012.

Barkley, M. P., Smedt, I. D., Van-Roozendael, M., Kurosu, T. P., Chance, K., Arneth, A., Hagberg, D., Guenther, A., Paulot, F., Marais, E., and Mao, J.: Top-down isoprene emissions over tropical South America inferred from SCIAMACHY and OMI formaldehyde columns, J. Geophys. Res.-Atmos., 118, 68496868, doi:10.1002/jgrd.50552, 2013.

Bhartia, P. K.: TOMS-V8 Total $\mathrm{O}_{3}$ Algorithm Theoretical Basis Document, OMI Algorithm Theoretical Basis Document, NASA Goddard Space Flight Center, Greenbelt, MD, USA, 2002.

Boersma, K. F., Eskes, H. J., and Brinksma, E. J.: Error analysis for tropospheric $\mathrm{NO}_{2}$ retrieval from space, J. Geophys. Res., 109, D04311, doi:10.1029/2003JD003962, 2004.

Boersma, K. F., Eskes, H. J., Veefkind, J. P., Brinksma, E. J., van der A, R. J., Sneep, M., van den Oord, G. H. J., Levelt, P. F., Stammes, P., Gleason, J. F., and Bucsela, E. J.: Near-real time retrieval of tropospheric $\mathrm{NO}_{2}$ from OMI, Atmos. Chem. Phys., 7, 2103-2118, doi:10.5194/acp-7-2103-2007, 2007.

Boersma, K. F., Eskes, H. J., Dirksen, R. J., van der A, R. J., Veefkind, J. P., Stammes, P., Huijnen, V., Kleipool, Q. L., Sneep, M., Claas, J., Leitão, J., Richter, A., Zhou, Y., and Brunner, D.: An improved tropospheric $\mathrm{NO}_{2}$ column retrieval algorithm for the Ozone Monitoring Instrument, Atmos. Meas. Tech., 4, 19051928, doi:10.5194/amt-4-1905-2011, 2011a.

Boersma, K. F., Braak, R., and van der A, R. J.: Dutch OMI $\mathrm{NO}_{2}$ (DOMINO) data product v2.0, HE5 data file user manual, $2011 \mathrm{~b}$.

Cai, Z., Liu, Y., Liu, X., Chance, K., Nowlan, C. R., Lang, R., Munro, R., and Suleiman, R.: Characterization and correction of Global Ozone Monitoring Experiment 2 ultraviolet measurements and application to ozone profile retrievals, J. Geophys. Res.-Atmos., 117, 2156-2202, doi:10.1029/2011JD017096, 2012

Cantrell, C. A., Davidson, J. A., McDaniel, A. H., Shetter, R. E., and Calvert, J. G.: Temperature-dependent formaldehyde cross sections in the near-ultraviolet spectral region, J. Phys. Chem., 94, 3902-3908, 1990.

Castellanos, P., Boersma, K. F., Torres, O., and de Haan, J. F.: OMI tropospheric $\mathrm{NO}_{2}$ air mass factors over South America: effects of biomass burning aerosols, Atmos. Meas. Tech. Discuss., 8, 2683-2733, doi:10.5194/amtd-8-2683-2015, 2015.

Chance, K., Palmer, P. I., Spurr, R. J. D., Martin, R. V., Kurosu, T. P., and Jacob, D. J.: Satellite observations of formaldehyde over North America from GOME, Geophys. Res. Lett., 27, 34613464, doi:10.1029/2000GL011857, 2000.

Curci, G., Palmer, P. I., Kurosu, T. P., Chance, K., and Visconti, G.: Estimating European volatile organic compound emissions using satellite observations of formaldehyde from the Ozone
Monitoring Instrument, Atmos. Chem. Phys., 10, 11501-11517, doi:10.5194/acp-10-11501-2010, 2010.

Danielson, J. and Gesch, D.: Global Multi-resolution Terrain Elevation Data 2010 (GMTED2010), Open-File Report 2011-1073, U.S. Geological Survey, 2011.

De Smedt, I., Müller, J.-F., Stavrakou, T., van der A, R., Eskes, H., and Roozendael, M. V.: Twelve years of global observation of formaldehyde in the troposphere using GOME and SCIAMACHY sensors, Atmos. Chem. Phys., 8, 4947-4963, doi:10.5194/acp-8-4947-2008, 2008

De Smedt, I., Van Roozendael, M., Stavrakou, T., Müller, J.-F., Lerot, C., Theys, N., Valks, P., Hao, N., and van der A, R.: Improved retrieval of global tropospheric formaldehyde columns from GOME-2/MetOp-A addressing noise reduction and instrumental degradation issues, Atmos. Meas. Tech., 5, 2933-2949, doi:10.5194/amt-5-2933-2012, 2012.

Dikty, S. and Richter, A.: GOME-2 on MetOp-A: Support for Analysis of GOME-2 In-Orbit Degradation and Impacts on Level 2 Data Products, http://www.iup.uni-bremen.de/doas/reports/ Final_Report_Level-2_Data_GOME-2_Degradation.pdf (last access: 2 October 2015), 2012.

Fayt, C., De Smedt, I., Letocart, V., Merlaud, A., Pinardi, G., and Van Roozendael, M.: QDOAS software user manual, Belgian Institute for Space Aeronomy, 1.00 Edn., 2011.

Fu, T.-M., Jacob, D. J., Palmer, P. I., Chance, K., Wang, Y. X., Barletta, B., Blake, D. R., Stanton, J. C., and Pilling, M. J.: Space-based formaldehyde measurements as constraints on volatile organic compound emissions in east and south Asia and implications for ozone, J. Geophys. Res., 112, 6312, doi:10.1029/2006JD007853, 2007.

González Abad, G., Liu, X., Chance, K., Wang, H., Kurosu, T. P., and Suleiman, R.: Updated Smithsonian Astrophysical Observatory Ozone Monitoring Instrument (SAO OMI) formaldehyde retrieval, Atmos. Meas. Tech., 8, 19-32, doi:10.5194/amt-8-192015, 2015.

Gonzi, S., Palmer, P. I., Barkley, M. P., Smedt, I. D., and Roozendael, M. V.: Biomass burning emission estimates inferred from satellite column measurements of HCHO: Sensitivity to coemitted aerosol and injection height, Geophys. Res. Lett., 38, L14807, doi:10.1029/2011GL047890, 2011.

Guenther, A., Karl, T., Harley, P., Wiedinmyer, C., Palmer, P. I., and Geron, C.: Estimates of global terrestrial isoprene emissions using MEGAN (Model of Emissions of Gases and Aerosols from Nature), Atmos. Chem. Phys., 6, 3181-3210, doi:10.5194/acp-63181-2006, 2006.

Heckel, A., Kim, S.-W., Frost, G., Richter, A., Trainer, M., and Burrows, J.: Influence of low spatial resolution a priori data on tropospheric $\mathrm{NO}_{2}$ satellite retrievals, Atmos. Meas. Tech., 4, 18051820, 2011.

Herman, J. R. and Celarier, E. A.: Earth surface reflectivity climatology at 340-380 nm from TOMS data, J. Geophys. Res., 102, 28003-28011, doi:10.1029/97JD02074, 1997.

Hewson, W., Bösch, H., Barkley, M. P., and De Smedt, I.: Characterisation of GOME-2 formaldehyde retrieval sensitivity, Atmos. Meas. Tech., 6, 371-386, doi:10.5194/amt-6-371-2013, 2013.

Kleipool, Q. L., Dobber, M. R., de Haan, J. F., and Levelt, P. F.: Earth surface reflectance climatology from 3 years of OMI data, J. Geophys. Res., 113, D18308, doi:10.1029/2008JD010290, 2008. 
Koelemeijer, R. B. A., de Haan, J. F., and Stammes, P.: A database of spectral surface reflectivity of the Earth in the range 335$772 \mathrm{~nm}$ derived from 5.5 years of GOME observations, J. Geophys. Res., 108, 4070, doi:10.1029/2002JD002429, 2003.

Köpke, P., Hess, M. Schult, I., and Shettle, E. P.: Global aerosol data set, Max-Planck-Institut für Meteorologie Hamburg, Germany, http://www.mpimet.mpg.de/fileadmin/publikationen/ Reports/MPI-Report_243.pdf (last access: 2 October 2015), 1997.

Kurosu, T. P., Chance, K., and Sioris, C.: Preliminary results for $\mathrm{HCHO}$ and $\mathrm{BrO}$ from the EOS-Aura Ozone Monitoring Instrument, in: Passive Optical Remote Sensing of the Atmosphere and Clouds IV, Proc. of SPIE, 5652, 166, doi:10.1117/12.578606, 2004.

Lee, C., Martin, R. V., van Donkelaar, A., O’Byrne, G., Krotkov, N., Richter, A., Huey, L. G., and Holloway, J. S.: Retrieval of vertical columns of sulfur dioxide from SCIAMACHY and OMI: Air mass factor algorithm development, validation, and error analysis, J. Geophys. Res., 114, doi:10.1029/2009JD012123, 2009.

Lin, J.-T., Martin, R. V., Boersma, K. F., Sneep, M., Stammes, P., Spurr, R., Wang, P., Van Roozendael, M., Clémer, K., and Irie, H.: Retrieving tropospheric nitrogen dioxide from the Ozone Monitoring Instrument: effects of aerosols, surface reflectance anisotropy, and vertical profile of nitrogen dioxide, Atmos. Chem. Phys., 14, 1441-1461, doi:10.5194/acp-14-1441-2014, 2014.

Loyola, D., Valks, P., Hao, N., Rix, M., and Slijkhuis, S.: Algorithm Theoretical Basis Document for GOME-2 Total Column Products of Ozone, $\mathrm{NO}_{2}$, tropospheric $\mathrm{NO}_{2}, \mathrm{BrO}$, $\mathrm{SO}_{2}, \mathrm{H}_{2} \mathrm{O}, \mathrm{HCHO}, \mathrm{OClO}$ and Cloud Properties, Tech. Rep. DLR/GOME-2/ATBD/01, EUMETSAT, available at: https:// wdc.dlr.de/sensors/gome2/DLR_GOME-2_ATBD_2A.pdf (last access: 2 October 2015), 2011.

Malicet, J., Daumont, D., Charbonnier, J., Parisse, C., Chakir, A., and Brion, J.: Ozone UV spectroscopy. II. Absorption crosssections and temperature dependence, J. Atmos. Chem., 21, 263273 doi:10.1007/BF00696758, 1995.

Mao, J., Paulot, F., Jacob, D. J., Cohen, R. C., Crounse, J. D., Wennberg, P. O., Keller, C. A., Hudman, R. C., Barkley, M. P., and Horowitz, L. W.: Ozone and organic nitrates over the eastern United States: Sensitivity to isoprene chemistry, J. Geophys. Res., 118, 11256-11268, doi:10.1002/jgrd.50817, 2013.

Marais, E. A., Jacob, D. J., Kurosu, T. P., Chance, K., Murphy, J. G., Reeves, C., Mills, G., Casadio, S., Millet, D. B., Barkley, M. P., Paulot, F., and Mao, J.: Isoprene emissions in Africa inferred from OMI observations of formaldehyde columns, Atmos. Chem. Phys., 12, 6219-6235, doi:10.5194/acp-12-62192012, 2012.

Martin, R. V., Chance, K., Jacob, D. J., Kurosu, T. P., Spurr, R. J. D., Bucsela, E., Gleason, J. F., Palmer, P. I., Bey, I., Fiore, A. M., Li, Q., Yantosca, R. M., and Koelemeijer, R. B. A.: An improved retrieval of tropospheric nitrogen dioxide from GOME, J. Geophys. Res., 107, 4437, doi:10.1029/2001JD001027, 2002.

Martin, R. V., Jacob, D. J., Yantosca, R. M., Chin, M., and Ginoux, P.: Global and regional decreases in tropospheric oxidants from photochemical effects of aerosols, J. Geophys. Res., 108, 4097, doi:10.1029/2002JD002622, 2003.

Meller, R. and Moortgat, G. K.: Temperature dependence of the absorption cross sections of formaldehyde between 223 and $323 \mathrm{~K}$ in the wavelength range $225-375 \mathrm{~nm}$, J. Geophys. Res., 105, 7089-7101, doi:10.1029/1999JD901074, 2000

Millet, D. B., Jacob, D. J., Turquety, S., Hudman, R. C., Wu, S., Fried, A., Walega, J, Heikes, B. G., Blake, D. R., Singh, H. B., Anderson, B. E., and Clarke, A. D.: Formaldehyde distribution over North America: Implications for satellite retrievals of formaldehyde columns and isoprene emission, J. Geophys. Res., 111, 2156-2202, doi:10.1029/2005JD006853, 2006.

Millet, D. B., Jacob, D. J., Boersma, F., Fu, T.-M., Kurosu, T. P., Chance, K., Heald, C. L., and Guenther, A.: Spatial distribution of isoprene emissions from North America dervied from formaldehyde column measurements by the OMI satellite sensor, J. Geophys. Res., 113, D02307, doi:10.1029/2007JD008950, 2008.

Olivier, J. G. J., Berdowski, J. J. M., Peters, J. A. H. W., Bakker, J., Visschedijk, A. J. H., and Bloos, J. P. J.: Applications of EDGAR. Including a description of EDGAR 3.2: reference database with trend data for 1970-1995, RIVM, Bilthoven, the Netherlands, RIVM report 773301 001/NRP report 410200 051, 2001.

Palmer, P. I., Jacob, D. J., Chance, K., Martin, R. V., Spurr, R. J. D., Kurosu, T. P., Bey, I., Yantosca, R., Fiore, A., and Li, Q.: Air mass factor formulation for spectroscopic measurements from satellites: Application to formaldehyde retrievals from the Global Ozone Monitoring Experiment, J. Geophys. Res., 106, 1453914550, doi:10.1029/2000JD900772, 2001.

Palmer, P. I., Jacob, D. J., Fiore, A. M., Martin, R. V., Chance, K., and Kurosu, T. P.: Mapping isoprene emissions over North America using formaldehyde column observations from space, J. Geophys. Res., 108, 4180, doi:110.1029/2002JD002153, 2003.

Palmer, P. I., Abbot, D. S., Fu, T.-M., Jacob, D. J., Chance, K., Kurosu, T., Guenther, A., Wiedinmyer, C., Stanton, J., Pilling, M., Pressley, S., Lamb, B., and Sumner, A. L.: Quantifying the seasonal and interannual variability of North American isoprene emissions using satellite observations of formaldehyde column, J. Geophys. Res., D12315, doi:10.1029/2005JD006689, 2006.

Paulot, F., Crounse, J. D., Kjaergaard, H. G., Kroll, J. H., Seinfeld, J. H., and Wennberg, P. O.: Isoprene photooxidation: new insights into the production of acids and organic nitrates, Atmos. Chem. Phys., 9, 1479-1501, doi:10.5194/acp-9-1479-2009, 2009a.

Paulot, F., Crounse, J. D., Kjaergaard, H. G., Kurten, A., St. Clair, J. M., Seinfeld, J. H., and Wennberg, P. O.: Unexpected Epoxide Formation in the Gas-Phase Photooxidation of Isoprene, Science, 325, 730-733, doi:10.1126/science.1172910, 2009 b.

Platt, U. and Stutz, J.: Differential Optical Absorption Spectroscopy, Physics of Earth and Space Environments, Springer, Berlin, Germany, 2008.

Popp, C., Wang, P., Brunner, D., Stammes, P., Zhou, Y., and Grzegorski, M.: MERIS albedo climatology for FRESCO+ $\mathrm{O}_{2}$ A-band cloud retrieval, Atmos. Meas. Tech., 4, 463-483, doi:10.5194/amt-4-463-2011, 2011.

Rienecker, M., Suarez, M. R., Todling, J. B., Takacs, L., Liu, H.-C., Gu, W., Sienkiewicz, M., Koster, R., Gelaro, R., Stajner, I., and Nielsen, J.: The GEOS-5 Data Assimilation System - Documentation of Versions 5.0.1, 5.1.0, and 5.2.0, Technical Report Series on Global Modeling and Data Assimilation, NASA Global Modeling and Assimilation Office, http://gmao.gsfc.nasa.gov/pubs/ docs/Rienecker491.pdf (last access: 2 October 2015), 2008. 
Rozanov, A., Rozanov, V., Buchwitz, M., Kokhanovsky, A., and Burrows, J. P.: SCIATRAN 2.0 - A new radiative transfer model for geophysical applications in the $175-2400 \mathrm{~nm}$ spectral region, Adv. Space Res., 36, 1015-1019, doi:10.1016/j.asr.2005.03.012, 2005.

Russell, A. R., Perring, A. E., Valin, L. C., Bucsela, E. J., Browne, E. C., Wooldridge, P. J., and Cohen, R. C.: A high spatial resolution retrieval of $\mathrm{NO}_{2}$ column densities from OMI: method and evaluation, Atmos. Chem. Phys., 11, 8543-8554, doi:10.5194/acp-11-8543-2011, 2011.

Schaub, D., Brunner, D., Boersma, K. F., Keller, J., Folini, D., Buchmann, B., Berresheim, H., and Staehelin, J.: SCIAMACHY tropospheric $\mathrm{NO}_{2}$ over Switzerland: estimates of $\mathrm{NO}_{x}$ lifetimes and impact of the complex Alpine topography on the retrieval, Atmos. Chem. Phys., 7, 5971-5987, doi:10.5194/acp-7-5971-2007, 2007.

Spurr, R.: Area-weighting tessellation for nadir-viewing spectrometers, Internal Technical Note, Harvard-Smithsonian Centre for Astrophysics, Cambridge, MA, USA, 2003.

Spurr, R. J. D.: A Simultaneous radiative transfer derivation of intensities and weighting functions in a general pseudo-spherical treatmentl, J. Quant. Spectrosc. Ra., 75, 129-175, 2002.

Stavrakou, T., Müller, J.-F., De Smedt, I., Van Roozendael, M., van der Werf, G. R., Giglio, L., and Guenther, A.: Evaluating the performance of pyrogenic and biogenic emission inventories against one decade of space-based formaldehyde columns, Atmos. Chem. Phys., 9, 1037-1060, doi:10.5194/acp-9-1037-2009, 2009a.

Stavrakou, T., Müller, J.-F., De Smedt, I., Van Roozendael, M., van der Werf, G. R., Giglio, L., and Guenther, A.: Global emissions of non-methane hydrocarbons deduced from SCIAMACHY formaldehyde columns through 2003-2006, Atmos. Chem. Phys., 9, 3663-3679, doi:10.5194/acp-9-3663-2009, 2009b.

Stavrakou, T., Müller, J.-F., Bauwens, M., De Smedt, I., Van Roozendael, M., Guenther, A., Wild, M., and Xia, X.: Isoprene emissions over Asia 1979-2012: impact of climate and land-use changes, Atmos. Chem. Phys., 14, 4587-4605, doi:10.5194/acp14-4587-2014, 2014.

Tilstra, L. G., Tuinder, O. N. E., and Stammes, P.: GOME-2 surface LER product - Algorithm Theoretical Basis Document, O3MSAF/KNMI/ATBD/003, KNMI, De Bilt, the Netherlands, 2014a.

Tilstra, L. G., Tuinder, O. N. E., and Stammes, P.: GOME2 surface LER product - O3M SAF Validation Report, SAF/03M/KNMI/VR/002, KNMI, De Bilt, the Netherlands, $2014 b$.
Valks, P., Pinardi, G., Richter, A., Lambert, J.-C., Hao, N., Loyola, D., Van Roozendael, M., and Emmadi, S.: Operational total and tropospheric $\mathrm{NO}_{2}$ column retrieval for GOME-2, Atmos. Meas. Tech., 4, 1491-1514, doi:10.5194/amt-4-1491-2011, 2011.

van der Werf, G. R., Randerson, J. T., Giglio, L., Collatz, G. J., Kasibhatla, P. S., and Arellano Jr., A. F.: Interannual variability in global biomass burning emissions from 1997 to 2004, Atmos. Chem. Phys., 6, 3423-3441, doi:10.5194/acp-6-3423-2006, 2006.

van Donkelaar, A., Martin, R. V., Leaitch, W. R., Macdonald, A. M., Walker, T. W., Streets, D. G., Zhang, Q., Dunlea, E. J., Jimenez, J. L., Dibb, J. E., Huey, L. G., Weber, R., and Andreae, M. O.: Analysis of aircraft and satellite measurements from the Intercontinental Chemical Transport Experiment (INTEX-B) to quantify long-range transport of East Asian sulfur to Canada, Atmos. Chem. Phys., 8, 2999-3014, doi:10.5194/acp-8-2999-2008, 2008.

Wang, P., Stammes, P., van der A, R., Pinardi, G., and van Roozendael, M.: FRESCO+: an improved $\mathrm{O}_{2}$ A-band cloud retrieval algorithm for tropospheric trace gas retrievals, Atmos. Chem. Phys., 8, 6565-6576, doi:10.5194/acp-8-6565-2008, 2008.

Wang, P., Tuinder, O. N. E., and Stammes, P.: Cloud retrieval algorithm for GOME-2: FRESCO+, Tech. Rep., KNMI, De Bilt, the Netherlands, 2010.

Wang, P., Tuinder, O. N. E., Tilstra, L. G., de Graaf, M., and Stammes, P.: Interpretation of FRESCO cloud retrievals in case of absorbing aerosol events, Atmos. Chem. Phys., 12, 90579077, doi:10.5194/acp-12-9057-2012, 2012.

Wittrock, F., Richter, A., Ladstäter-Weißenmayer, A., and Burrows, J. P.: Global observations of formaldehyde, in: European Space Agency, (Special Publication) ESA SP, Noordwijk, the Netherlands, 1358-1362, 2000.

Wittrock, F., Richter, A., Oetjen, H., Burrows, J. P., Kanakidou, M., Myriokefalitakis, S., Volkamer, R., Beirle, S., Platt, U., and Wagner, T.: Simultaneous global observations of glyoxal and formaldehyde from space, Geophys. Res. Lett., 33, L16804, doi:10.1029/2006GL026310, 2006.

Zhou, Y., Brunner, D., Boersma, K. F., Dirksen, R., and Wang, P.: An improved tropospheric $\mathrm{NO}_{2}$ retrieval for OMI observations in the vicinity of mountainous terrain, Atmos. Meas. Tech., 2, 401-416, doi:10.5194/amt-2-401-2009, 2009.

Zhou, Y., Brunner, D., Spurr, R. J. D., Boersma, K. F., Sneep, M., Popp, C., and Buchmann, B.: Accounting for surface reflectance anisotropy in satellite retrievals of tropospheric $\mathrm{NO}_{2}$, Atmos. Meas. Tech., 3, 1185-1203, doi:10.5194/amt-3-11852010, 2010. 